(C) 2022, The Authors. Published by Elsevier Inc. and Fass Inc. on behalf of the American Dairy Science Association ${ }^{\circledR}$. This is an open access article under the CC BY license (http://creativecommons.org/licenses/by/4.0/).

\title{
Camel milk-derived probiotic strains encapsulated in camel casein and gelatin complex microcapsules: Stability against thermal challenge and simulated gastrointestinal digestion conditions
}

\author{
Aarthi Devarajan, ${ }^{1 *}$ Priti Mudgil, ${ }^{1 *}$ ๑ Fatima Aldhaheri, ${ }^{1}$ Fathala Hamed, ${ }^{2}$ ๑ Sushil Dhital, ${ }^{3}$ \\ and Sajid Maqsood ${ }^{1}+$ (D) \\ ${ }^{1}$ Department of Food Science, College of Agriculture and Veterinary Medicine, United Arab Emirates University, Al Ain, 15551, \\ United Arab Emirates \\ ${ }^{2}$ Department of Physics, College of Science, United Arab Emirates University, Al Ain, 15551, United Arab Emirates \\ ${ }^{3}$ Department of Chemical Engineering, Monash University, Clayton, VIC 3800, Australia
}

\begin{abstract}
Probiotics have received increased attention due to their nutritional and health-promoting benefits. However, their viability is often impeded during food processing as well as during their gastrointestinal transit before reaching the colon. In this study, probiotic strains Lactobacillus rhamnosus MF00960, Pediococcus pentosaceus MF000967, and Lactobacillus paracasei DSM20258 were encapsulated within sodium alginate, camel casein (CC), camel skin gelatin (CSG) and CC:CSG (1:1 wt/wt) wall materials. All 3 strains in encapsulated form showed an enhanced survival rate upon simulated gastrointestinal digestion compared with free cells. Among the encapsulating matrices, probiotics embedded in $\mathrm{CC}$ showed higher viability and is attributed to less porous structure of $\mathrm{CC}$ that provided more protection to entrapped probiotics cells. Similarly, thermal tolerance at $50^{\circ} \mathrm{C}$ and $70^{\circ} \mathrm{C}$ of all 3 probiotic strains were significantly higher upon encapsulation in CC and CC:CSG. Scanning electron microscope micrographs showed probiotic strains embedded in the dense protein matrix of CC and CSG. Fourier-transform infrared spectroscopy showed that CC- and CSG-encapsulated probiotic strains exhibited the amide bands with varying intensity with no significant change in the structural conformation. Probiotic strains encapsulated in CC and CC:CSG showed higher retention of inhibitory properties against $\alpha$-glucosidase, $\alpha$-amylase, dipeptidyl peptidase-IV, pancreatic lipase, and cholesteryl esterase compared with free cells upon
\end{abstract}

Received May 15, 2021.

Accepted November 9, 2021.

*These authors contributed equally to this work.

†Corresponding author: sajid.m@uaeu.ac.ae exposure to simulated gastrointestinal digestion conditions. Therefore, $\mathrm{CC}$ alone or in combination with CSG as wall materials provided effective protection to cells, retained their bioactive properties, which was comparable to sodium alginate as wall materials. Thus, $\mathrm{CC}$ and CC:CSG can be an efficient wall material for encapsulation of probiotics for food applications.

Key words: camel milk, Lactobacillus, microencapsulation, in vitro digestion, bioactive properties

\section{INTRODUCTION}

Probiotic lactic acid bacteria have been employed in the design of various functional foods. To retain the viability of probiotic microorganism during food processing and storage, as well as in the gastrointestinal transit, probiotics are encapsulated in various matrices (Fernanda et al., 2016). The encapsulation methods as well as nature, type, or characteristic of encapsulating matrices are critical in maintaining the viability of probiotic bacteria and their subsequent health effects (Ahmad et al., 2019b).

Commonly used encapsulation matrices such as carbohydrates, proteins, and their combinations have been examined to maintain probiotic viability and stability. Polysaccharides, such as sodium alginate, chitosan, starch, methylcellulose, and sodium carboxymethylcellulose, exhibit several advantages, including better chemical stability, film-forming ability, stabilization, and better protection to the encapsulated probiotics in the adverse environmental conditions, especially under the gastrointestinal condition (Kanmani et al., 2011). In this regard, some studies have indicated the efficacy of gelatin as a potential encapsulating matrix because of its properties such as thermally reversible gelling behavior, membrane-forming ability, biocompatibility, and nontoxicity (Petraitytè and Sipailienè, 2019). Simi- 
larly, milk proteins such as caseins and whey proteins are also recognized as valuable biological macromolecules with high nutritional and excellent functional properties. These milk proteins have properties such as binding small molecules, self-assembly, excellent gelation, pH-responsive gel swelling behavior, and ability to interact with other polymers for the formation of complexes (Singh et al., 2019). In addition, probiotics proliferate well in dairy-based media because of the lactose-hydrolyzing enzyme and proteolytic system involved in casein utilization, which nourishes the probiotic cells with essential source of carbon and amino acids for their development (Yeo et al., 2011). Among different sources of proteins, bovine milk proteins and bovine or porcine gelatin are widely used as an encapsulating material. However, studies pertaining to camel milk proteins and camel skin gelatin (CSG) are limited (Ahmad et al., 2019b). Until today, predominant number of studies related to gelatin and its utilization for encapsulation are concentrated upon porcine, bovine and fish gelatin. The present study aims to use camel casein (CC) proteins and camel gelatin as potential alternative wall material for encapsulating novel camel milk-derived probiotic strains and compared the results with widely used encapsulant sodium alginate (SA). The probiotic cell viability during encapsulation upon their transit through simulated digestion and their thermal tolerance are thoroughly investigated. Subsequently, the effect of the probiotic strains encapsulated in casein and gelatin matrices on in vitro inhibition of enzymatic biomarkers related to diabetes $[\alpha$-glucosidase $(\mathbf{A G})$, $\alpha$-amylase, dipeptidyl peptidase (DPP-IV)] and with obesity [pancreatic lipase (PL) and cholesteryl esterase (CE)] after simulated gastrointestinal digestion were also investigated. This study will facilitate future applications of encapsulated probiotics using novel source of protein ( $\mathrm{CC}$ and gelatin) as wall material and may find wide scope in the functional food industry.

\section{MATERIALS AND METHODS}

\section{Materials}

The probiotic strains Lactobacillus rhamnosus MF00960 and Pediococcus pentosaceus MF000967 isolated from raw camel milk obtained from local farms of Al Ain, Abu Dhabi, United Arab Emirates. A standard probiotic strain of Lactobacillus paracasei DSM20258 was procured from the Leibniz Institute DSMZ, German Collection of Microorganisms and Cell Cultures GmbH. The medium de Man, Rogosa, and Sharpe (MRS) was purchased from HiMedia. All other reagents and chemicals used in this study were of analytical grade and procured from Sigma-Aldrich.

\section{Isolation and Identification of Probiotic Strains}

Isolation of probiotic strains Lactobacillus rhamnosus MF00960 and Pediococcus pentosaceus MF000967 was carried out from raw camel milk obtained from healthy female camels (mid-lactation stage, 4-6 mo), from local farms located in eastern region of Abu Dhabi, United Arab Emirates. All samples were collected in sterile glass bottles containing MRS broth, samples were brought immediately to laboratory under refrigeration conditions and incubated at $37^{\circ} \mathrm{C}$, overnight that allowed the enrichment of lactic acid bacteria. Thereafter, serial dilutions were prepared and pour plated with MRS agar supplemented with $(0.05 \mu \mathrm{g} / \mathrm{mL})$ of bromocresol purple and L-cysteine hydrochloride as described by Ahmad et al. (2019b) and incubated at $37^{\circ} \mathrm{C}$ for $48 \mathrm{~h}$ under anaerobic conditions. Well-isolated colonies with different colony morphologies were selected, whereas gram-positive and catalase negative isolates were further purified and identified using $16 \mathrm{~S}$ rRNA gene amplification using universal eubacteria primers: 27 F (5'-AGAGTTTGATCMTGGCTCAG-3') and 1492R (5'-TACGGYTACCTTGTTACGACTT-3'). Upon PCR amplification, the PCR product was sequenced through an external DNA sequencing service (1st Base). Identification of isolated strains was carried out through sequence analysis by performing Basic Local Alignment Search Tool for Nucleotides (BLAST-N) against existing sequences in the National Center for Biotechnology Information (NCBI) database (https:/ /blast.ncbi.nlm.nih.gov/Blast.cgi) and sequences were submitted to NCBI database.

\section{Extraction of Casein and Gelatin}

For the extraction of CSG, a composite sample of skins from healthy camels (Camelius dromedaries) was procured from a local slaughterhouse located in Al Ain, Abu Dhabi, United Arab Emirates. Camel skin gelatin was extracted using an alkali-based pretreatment and extraction method that has been previously optimized by our group (Abuibaid et al., 2020; Fawale et al., 2021). Extracted CSG samples were lyophilized using freeze dryer (Lypho-II, Telstar) and stored at $-20^{\circ} \mathrm{C}$ until further analysis.

Camel milk caseins were separated from skimmed camel milk sample using an isoelectric acid precipitation of caseins with adjustment of $\mathrm{pH}$ to 4.2 as previously described by Kamal et al. (2018) with slight modifications. Briefly, a composite sample of raw milk obtained from young healthy female camels was skimmed twice by centrifugation at $4,255 \times g$ at $15^{\circ} \mathrm{C}$ for $15 \mathrm{~min}$. Thereafter, the $\mathrm{pH}$ was adjusted to 4.0 using $6 \mathrm{~N} \mathrm{HCl}$ and the mixture was allowed to rest at $4^{\circ} \mathrm{C}$ for $2 \mathrm{~h}$ 
to ensure better precipitation of CC. The casein precipitates were separated using centrifugation at 4,255 $\times g$ at $4^{\circ} \mathrm{C}$ for $15 \mathrm{~min}$. The pellet obtained was washed thrice with deionized water and $\mathrm{pH}$ was readjusted to 7.0 using $1 \mathrm{~N} \mathrm{NaOH}$. The neutralized casein samples were then freeze-dried and stored at $-20^{\circ} \mathrm{C}$ until their further use in encapsulation experiments.

\section{Preparation of Probiotic Cell Suspension for Encapsulation}

For encapsulation, 24-h-old cultures of probiotic strains which were freshly activated after propagation by 3 successive transfers in MRS broth were used. All the probiotic strains used in the study were grown at $37^{\circ} \mathrm{C}$ and cells were harvested at their late log phase through centrifugation at $5,000 \times g$ at $10^{\circ} \mathrm{C}$ for $5 \mathrm{~min}$ and cell pellets were washed thrice with sterile distilled water and recentrifuged to ensure the complete removal of spent MRS broth. The cells obtained were resuspended in sterile distilled water. The cell suspensions thus obtained was immediately used for microencapsulation and one portion from each strain was kept as free cells control.

\section{Encapsulation of Probiotic Cells}

Encapsulation of probiotic strains within different wall materials was carried out as described by Ahmad et al. (2019b) with slight modifications. Briefly, SA was used as a base material in all encapsulation procedure. Sodium alginate $(2 \%)$ was used as a control, whereas other wall materials such as CC, CSG, and CC:CSG gelatin $(1: 1 \mathrm{wt} / \mathrm{wt})$ at $2 \%$ were prepared by mixing them with $0.5 \% \mathrm{SA}$ as base solutions. Upon complete dissolution of wall materials in sterile deionized water at $50^{\circ} \mathrm{C}$ under constant stirring using magnetic stirrer, the mixtures were homogenized at 15,000 rpm for $2 \mathrm{~min}$ to obtain a homogeneous solution. The solutions were then filtered using $0.2-\mu \mathrm{m}$ filters and stored at $4^{\circ} \mathrm{C}$ until further use. The mixtures obtained above were then mixed with probiotic cell suspensions of L. rhamnosus, $P$. pentosaceus, and L. paracasei. Cell counts in the final mixture were enumerated using pour plate technique on MRS agar after incubation at $37^{\circ} \mathrm{C}$ for $48 \mathrm{~h}$ under aerobic conditions. The mixtures were then poured as minute droplets into calcium lactate (4\%) solution to obtain hardened cell suspensions in the form of microcapsules. The microcapsules were freeze-dried using Telstar Freeze dryer (Telstar) at temperature $-80^{\circ} \mathrm{C}$, 0.1 bar pressure. The resulting freeze-dried powder were subsequently stored at $-20^{\circ} \mathrm{C}$ in airtight sterile containers for further studies.

\section{Bacterial Death Cycle and Encapsulation Efficiency}

Viability of probiotic cells upon encapsulation was determined following the protocol described by Vaziri et al. (2018). Briefly, the powdered samples were suspended in sterile peptone water at a concentration of $2 \%$ and cells were allowed to release through homogenization at 15,000 rpm for $1 \mathrm{~min}$. Thereafter, viable cells were enumerated on MRS agar using pour plating technique and colony forming units were determined following an incubation at $37^{\circ} \mathrm{C}$ for $48 \mathrm{~h}$ under aerobic conditions. Bacterial death cycles and encapsulation efficiency (EE) were determined using the following equations (Vaziri et al., 2018):

$$
\begin{aligned}
& \text { Bacterial death cycles }= \\
& \log \mathrm{cfu} / \mathrm{g}(\text { before })-\log \mathrm{cfu} / \mathrm{g}(\text { after }) \\
& \mathrm{EE}(\%)=\frac{\log \mathrm{cfu} / \mathrm{g}(\text { after })}{\log \mathrm{cfu} / \mathrm{g}(\text { before })} \times 100,
\end{aligned}
$$

where $\log \mathrm{cfu} / \mathrm{g}$ (before) and log cfu/g (after) refer to the number of viable cells before and after encapsulation.

\section{Cell Viability upon Simulated Gastrointestinal Digestion Conditions}

A 2-step static model of simulated gastrointestinal digestion (SGID) was adapted from Ahmad et al. (2019a,b). Simulated gastric juice (SGJ) was prepared by dissolving $3 \mathrm{~g} / \mathrm{L}$ pepsin (cat. no. P7012, $\geq 2,500$ units/mg protein, Sigma) in sterile $\mathrm{NaCl}$ solution (9 $\mathrm{g} / \mathrm{L}$ ) and the $\mathrm{pH}$ was adjusted to 2.0 with $1.0 \mathrm{M} \mathrm{HCl}$. Simulated intestinal juice (SIJ) was prepared by dissolving $3 \mathrm{~g} / \mathrm{L}$ bile salts (cat. no. B3883, Bile bovine, dried, unfractionated, Sigma) and $10 \mathrm{~g} / \mathrm{L}$ of pancreatin (cat. no. P7545, $\geq 3$ USP specification, Sigma) in phosphate-buffered saline, $\mathrm{pH}$ was maintained at 8.0 with $\mathrm{NaOH}$ solution $(0.1 M)$. Further, encapsulated and free cells corresponding to an approximate $10 \mathrm{log} \mathrm{cfu} / \mathrm{g}$ were placed in sterile glass test tubes $(\mathrm{n}=3)$ to which 10 $\mathrm{mL}$ of SGJ was added and incubation was carried out at $37^{\circ} \mathrm{C}$ for $2 \mathrm{~h}$ under constant stirring conditions at $100 \mathrm{rpm}$. Following this, the tubes were centrifuged at $5,000 \times g$ for $10 \mathrm{~min}$ at room temperature to remove spent SGJ and to recover the sediments with released cells. The pellets were replenished with $10 \mathrm{~mL}$ of SIJ and tubes were then incubated again at $37^{\circ} \mathrm{C}$ under constant agitation for $4 \mathrm{~h}$. The viable count $(\log \mathrm{cfu} / \mathrm{g})$ was determined by plating onto MRS agar after homogenization and after serial dilutions in sterile peptone 
water with incubation at $37^{\circ} \mathrm{C}$ for $48 \mathrm{~h}$ under aerobic conditions.

\section{Thermal Resistance}

The thermal resistance of encapsulated probiotics was determined according to protocol previously described by Praepanitchai et al. (2019). Briefly, encapsulated and free cells corresponding to an approximate $8 \mathrm{log}$ cfu were transferred into sterile glass tubes containing $10 \mathrm{~mL}$ of sterile peptone water and subjected to heat treatments at 50 and $70^{\circ} \mathrm{C}$ for $15 \mathrm{~min}$. Viable cell counts were determined following homogenization for 2 min followed by plating with MRS agar and plates were then incubated at $37^{\circ} \mathrm{C}$ for $48 \mathrm{~h}$ under aerobic conditions.

\section{Fourier-Transform Infrared Spectroscopy}

Fourier-transform infrared spectroscopy (FTIR) spectra of encapsulated freeze-dried samples were recorded with Spectrum2 FTIR spectrophotometer (Perkin Elmer) with mid-IR range with triglycine sulphate (MIR-TGS) detector for improved signal-to-noise ratio and increased interferometer scanning speed. All the spectra were collected with Perkin Elmer Spectrum software at a scanning range of 500 to $4,000 \mathrm{~cm}^{-1}$ at a resolution of $1 \mathrm{~cm}^{-1}$ and the spectra were baseline corrected before analysis (Ahmad et al., 2019a). The peaks belonging to different functional groups were identified using tool IR Wizard $2019^{\beta}$ available at http://www .science-and-fun.de/tools/.

\section{Scanning Electron Microscopy}

The microstructure of the freeze-dried encapsulated probiotic strains was evaluated using a scanning electron microscope (JEOL Neo Scope JCM-SEM, model MP-19020NCTR). Encapsulated bacterial strains were fixed on aluminum stubs through the carbon tape and DC sputtered with the gold of $8 \mathrm{~nm}$ under the atmosphere of argon. The microscopic observations were performed at $15 \mathrm{kV}$ and $1,000 \times$ magnification.

\section{Effect of SGID on Bioactivities of Free and Encapsulated Cells}

Preparation of Cell Extracts. In vitro health-related bioactive properties of probiotic strains (L. rhamnosus, P. pentosaceus, and L. paracasei) were studied by subjecting free and encapsulated cell mass to SGID conditions. Untreated free cells were kept as control.
The cell mass obtained upon complete SGID treatment were suspended in $5 \%$ sterile peptone water followed by vortexing the cell suspensions, which were further incubated at $37^{\circ} \mathrm{C}$ for $6 \mathrm{~h}$ to produce the metabolites and disrupted ultrasonically using 3 - to 5 -s pulses for 5 min in an ice bath using Double-Step 1/8" Microtip Probe-based Ultra-sonifier (Branson SFX550 Sonifier). Cell debris was removed by centrifugation at 10,000 $\times$ $g$ for 15 min at room temperature, and the supernatant obtained was stored at $-20^{\circ} \mathrm{C}$ for performing bioactivity assays.

Bioactive Properties of Bacterial Cell Extract as Affected by SGID and Encapsulation. The bioactive properties of cellular extracts from probiotic strains were determined for in vitro antidiabetic activities via inhibition of enzymatic markers such as AG $(0.2 \mathrm{U} / \mathrm{mL})$, pancreatic $\alpha$-amylase (PAA; $1 \mathrm{mg} /$ $\mathrm{mL})$, and DPP-IV $(0.01 \mathrm{U} / \mathrm{mL})$ inhibition activity using protocols from Zhang et al. (2015), Mudgil et al. (2019), and Nongonierma et al. (2018), respectively, with p-nitrophenyl $\alpha$-D-glucopyranoside $(10 \mathrm{~m} M)$, p-nitrophenyl $\alpha$-D-maltohexaoside $(5 \mathrm{~m} M)$, and Glypro-p-nitroanilide $(5 \mathrm{mM})$ as AG, PAA, and DPP-IV substrates, respectively. In vitro anti-obesity activities were determined via inhibition of PL $(1 \mathrm{mg} / \mathrm{mL})$ and CE $(10 \mu \mathrm{g} / \mathrm{mL})$ following the protocol of Ajayi et al. (2021), with p-nitrophenyl butyrate $(5 \mathrm{mM})$ as substrate. Briefly, $50 \mu \mathrm{L}$ of sample was first mixed with 50 $\mu \mathrm{L}$ of substrate and reaction was initiated by addition of $50 \mu \mathrm{L}$ of enzyme. The microplates were incubated at $37^{\circ} \mathrm{C}$ for $30 \mathrm{~min}$ and absorbance was measured at 405 nm using microplate reader (Multiskan Sky, ThermoFisher Scientific).

Individual sample blanks were also run by replacing enzyme volume with same amount of the respective buffer to eliminate the background absorbance produced from samples. Enzyme inhibition assays were performed, and percentage of enzyme inhibition was calculated using Equation 3.

$$
\text { Enzyme Inhibition }(\%)=\left[1-\left(\frac{C-D}{A-B}\right)\right] \times 100
$$

where $A$ is control, $B$ is control blank, $C$ is sample, and $D$ is sample blank, referring to the absorbance values of reaction vials containing enzyme, without enzyme, enzyme with sample, and without enzyme but with sample, respectively. Substrate was present in all reactions. When enzyme and samples were not present in a reaction the same amount was replaced with respective buffer for each assay. 


\section{Statistical Analysis}

All experiments and analysis were run in triplicate. Three different batches of microcapsules for each probiotic strain using each wall material were produced. Data were recorded as mean \pm standard deviation and were subjected to one-way ANOVA. Multiple comparisons were performed by Tukey's multiple comparison test with statistical significance set at $P<0.05$. All analyses were performed using SPSS 26.0 (IBM Corp.).

\section{RESULTS AND DISCUSSION}

\section{Effect of Different Wall Materials on Survival Percentage, Bacterial Cell Death Cycle, and EE}

Effect of different wall materials such as SA, CC, CSG, and CC:CSG on the cell viability and bacterial death cycle of free and encapsulated probiotic strains L. rhamnosus, P. pentosaceus, and L. paracasei after the encapsulation process was investigated and results obtained are presented in Table 1. Encapsulation efficiency for 3 probiotic strains upon encapsulation were found in range of 91.3 to $97.4 \%$ for L . rhamnosus, 85.5 to $91.6 \%$ for P. pentosaceus, and 90.3 to $99.2 \%$ for $L$. paracasei. Although the cell death cycle remained in the range of 0.08 to $1.7 \mathrm{log} \mathrm{cfu} / \mathrm{g}$. Maximum reduction of cell $\log$ count was recorded for $P$. pentosaceus encapsulated in SA $(1.70 \pm 0.05)$, whereas least was seen for L. paracasei encapsulated in CC $(0.08 \pm 0.001$; $P<0.05)$. Overall, it was observed that maximum protection (lower cell death cycle) to all 3 probiotics was provided upon probiotic encapsulation within CC followed closely by encapsulation in the CC:CSG. Cell death cycle counts demonstrated by probiotic cells encapsulated in CC and CC:CSG were significantly lower than those encapsulated in SA and CSG $(P<0.05)$. Using CSG alone for encapsulation results in cell death cycle which was very close to SA encapsulated cells $(P$ $<0.05)$.

Milk proteins are known to be a good choice for microencapsulation of bioactive compounds and probiotics (Abd El-Salam and El-Shibiny, 2015), as they are flexible to entrap different types of probiotic cells, thus enhancing their viability. In addition, intrinsic properties of milk proteins such as better gelation and high viscosity provides better dispersion and higher protection for the entrapped probiotics. Milk proteins also possess better buffering capacity to protect cells from harsh environments. Moreover, milk proteins are known to have wide range of functional and bioactive properties with synergistic benefits for cell viability. In a study, Burgain et al. (2013) reported $99.0 \%$ of bacterial survival with an $\mathrm{EE}$ of $97.0 \%$ for L. rhamnosus encapsulated with micellar casein and denatured whey protein, which corroborates with the results of present study. Moreover, Prasanna and Charalampopoulos (2018) also reported that encapsulation of Bifidobacterium longum in SA-bovine casein and SA-goat casein resulted in entrapment and survival of approximately 94.9 and $95.3 \%$ cells, respectively.

Gelatin is also considered to be an excellent macromolecule for encapsulation of bioactive compounds and probiotic cells due to their amphoteric nature $(\mathrm{Li}$ et al., 2009). The results obtained from the present study indicated that CSG was able to protect probiotic cells (P. pentosaceus and L. paracasei) more effectively with lower cell death cycle and higher EE, compared with that of cells encapsulated in SA $(P<0.05)$. With CSG encapsulation, the survivability of L. rhamnosus, L. pentosaceus, and L. paracasei upon freeze-drying was $91.3,87.0$ and $97.9 \%$, respectively. The results are comparable to survival of $L$. rhamnosus GG (81.02 \pm $0.19 \%$ ) upon encapsulation using fish gelatin (Jiang et al., 2020). Furthermore, microencapsulation of Bifidobacterium longum in gelatin conferred better survivability than a combination of gum arabic and starch, as wall material (Lian et al., 2003). Survivability percent of Saccharomyces cerevisiae var. boulardii encapsulated in gelatin was reported to be $91.55 \%$ upon encapsulation (Arslan et al., 2015).

Moreover, synergistic application of CC to CSG for encapsulation proved to further improve the EE in $L$. rhamnosus, L. pentosaceus, and L. paracasei to the level of 96.0,91.0, and $98.2 \%$, respectively. These EE values for all 3 strains of probiotics encapsulated in CS:CSG were higher compared with those encapsulated in CSG alone and SA $(P<0.05)$.

The EE of CSG reported in the current study $(87-97 \%)$ is higher than the values reported when $B i$ fidobacterium pseudocatenulatum was encapsulated in porcine gelatin and bovine gelatin conjugated with SA and genipin which resulted in EE of 45.94 and $57.66 \%$, respectively (Khalil et al., 2019). Zhao et al. (2018) reported that whey protein isolate/gum arabic at $\mathrm{pH}$ 4.5 resulted in substantial reduction in viability during spray drying and concluded that gelatin, an alkaline protein as an ideal protein matrix for encapsulation by coacervation with optimum $\mathrm{pH}$ (8.0). Sodium caseinate when used in encapsulation of probiotic bacteria might be able to decrease heat stress of spray drying and render a hydrophobic barrier during storage and digestion of probiotics (Zhao et al., 2020). It has been reported that gelatin in conjugation with casein as wall material for probiotic bacteria (Lactobacillus reuteri) demonstrated the higher protection compared with casein alone, gelatin/gum arabic conjugate and gelatin alone when probiotic was subject to gastrointestinal diges- 
Table 1. Effect of different wall materials on cell death cycle, encapsulation efficiency, total survivability upon simulated gastrointestinal digestion (SGID) and their thermal tolerance at 50 and $70^{\circ} \mathrm{C}$

\begin{tabular}{|c|c|c|c|c|c|c|}
\hline Probiotic strain & $\begin{array}{l}\text { Wall } \\
\text { material }^{2}\end{array}$ & $\begin{array}{l}\text { Cell death cycle } \\
\quad(\log \mathrm{cfu} / \mathrm{g})\end{array}$ & $\begin{array}{l}\text { Encapsulation } \\
\text { efficiency (\%) }\end{array}$ & $\begin{array}{c}\text { Survivability } \\
\text { upon SGID (\%) }\end{array}$ & \multicolumn{2}{|c|}{ Thermal tolerance (log cfu/g) } \\
\hline Lactobacillus rhamnosus & $\mathrm{FC}$ & - & - & $43.91 \pm 0.09^{\mathrm{a}}$ & ND & ND \\
\hline \multirow{3}{*}{ MF00960 } & $\mathrm{CC}$ & $0.27 \pm 0.02^{\mathrm{a}}$ & $97.4 \pm 0.19^{\mathrm{d}}$ & $99.01 \pm 1.25^{\mathrm{e}}$ & $7.72 \pm 0.02^{\mathrm{b}}$ & $7.09 \pm 0.04^{\mathrm{b}}$ \\
\hline & CSG & $0.96 \pm 0.01^{\mathrm{d}}$ & $91.3 \pm 0.11^{\mathrm{a}}$ & $69.32 \pm 0.12^{\mathrm{b}}$ & $6.22 \pm 0.4^{\mathrm{a}}$ & $6.11 \pm 0.42^{\mathrm{a}}$ \\
\hline & $\mathrm{CC}: \mathrm{CSG}$ & $0.44 \pm 0.03^{\mathrm{b}}$ & $96.0 \pm 0.28^{\mathrm{c}}$ & $87.54 \pm 0.76^{\mathrm{d}}$ & $7.67 \pm 0.29^{\mathrm{b}}$ & $6.71 \pm 0.06^{\mathrm{al}}$ \\
\hline \multirow{3}{*}{ MF00096 } & $\mathrm{CC}$ & $0.98 \pm 0.01^{\mathrm{a}}$ & $91.6 \pm 0.08^{\mathrm{c}}$ & $97.93 \pm 0.36^{\mathrm{c}}$ & $7.65 \pm 0.03^{\mathrm{c}}$ & $6.14 \pm 0.39^{\mathrm{c}}$ \\
\hline & CSG & $1.52 \pm 0.01^{\mathrm{b}}$ & $87.0 \pm 0.09^{\mathrm{b}}$ & $99.66 \pm 0.16^{\mathrm{d}}$ & $6.98 \pm 0.01^{\mathrm{b}}$ & $5.64 \pm 0.46^{\mathrm{bc}}$ \\
\hline & CC:CSG & $1.05 \pm 0.01^{\mathrm{a}}$ & $91.0 \pm 0.06^{\mathrm{c}}$ & $98.55 \pm 0.31^{\mathrm{c}}$ & $7.62 \pm 0.17^{\mathrm{c}}$ & $6.01 \pm 0.19^{\mathrm{bc}}$ \\
\hline Lactobacillus paracasei & $\mathrm{FC}$ & - & - & $72.44 \pm 0.12^{\mathrm{a}}$ & $5.66 \pm 0.19^{\mathrm{a}}$ & $5.68 \pm 0.13^{\mathrm{a}}$ \\
\hline \multirow[t]{3}{*}{ DSM 20258} & SA & $1.09 \pm 0.01^{\mathrm{d}}$ & $90.3 \pm 0.10^{\mathrm{a}}$ & $87.39 \pm 0.11^{\mathrm{b}}$ & $6.67 \pm 0.04^{\mathrm{b}}$ & $6.89 \pm 0.02^{\mathrm{b}}$ \\
\hline & $\mathrm{CC}$ & $0.08 \pm 0.001^{\mathrm{a}}$ & $99.2 \pm 0.17^{\mathrm{d}}$ & $92.62 \pm 0.25^{\mathrm{e}}$ & $7.92 \pm 0.02^{\mathrm{d}}$ & $8.35 \pm 0.32^{\mathrm{c}}$ \\
\hline & CSG & $0.25 \pm 0.01^{\mathrm{c}}$ & $97.7 \pm 0.14^{\mathrm{b}}$ & $89.88 \pm 0.11^{\mathrm{c}}$ & $7.51 \pm 0.22^{\mathrm{c}}$ & $5.86 \pm 0.25^{\mathrm{a}}$ \\
\hline
\end{tabular}

${ }^{\mathrm{a}-\mathrm{e}}$ Means with different superscript letters in a column represent significant difference $(P<0.05)$ between different samples within each probiotic strain.

${ }^{1}$ Values represent mean $\pm \mathrm{SD}(\mathrm{n}=3)$. ND $=$ not detected (no inhibitory activity detected).

${ }^{2} \mathrm{FC}=$ free cells; $\mathrm{SA}=$ sodium alginate; $\mathrm{CC}=$ camel casein; $\mathrm{CSG}=$ camel skin gelatin; $\mathrm{CC}$ :CGS $=1: 1$ (wt/wt) encapsulated probiotic strains

tion, and heat stress (Zhao et al., 2020). These results strongly indicate the advantage of using hetero-protein conjugations and effective role of caseins in enhancing probiotic resistance against external factors such as drying, heating, and digestion conditions.

\section{Viability of Encapsulated Probiotics Under Simulated Digestion}

Probiotics are often challenged by their inactivation during their passage through the gastrointestinal tract and $\mathrm{pH}$ fluctuations and hence do not reach the absorption site, the colon in an intact form and enough numbers ( $\mathrm{Gu}$ et al., 2019). For any encapsulating wall material, it is essential that they keep probiotic cells protected under gastric conditions while releasing the probiotic cells under intestinal conditions, thus enabling probiotics to reach the colon intact to exhibit their bioactive properties.

Upon SGID transit, the viable cells percentage was higher in the encapsulated probiotics than the free cell suspension of L. rhamnosus, P. pentosaceus, and L. paracasei $(P<0.05$; Table 1$)$. The present study shows that the viability of free probiotic cells greatly reduced when compared with the encapsulated probiotics which exhibited greater resistance under simulated gastrointestinal conditions. The present findings revealed that $\mathrm{CC}$ is an efficient encapsulant for L. rhamnosus with the viable cells percentage of $99.01 \%$ followed by CC: CSG mixture with $87.54 \%$ cell viability. On the other hand, maximum cell viability of 99.66 and $98.55 \%$ was achieved for $P$. pentosaceus when encapsulated with
CSG and CC:CSG as encapsulating matrix. Similarly, CC-based encapsulation of $L$. paracasei produced the microcapsules with highest viability of $92.62 \%$. The findings suggest that the probiotic cells inside the matrices of $\mathrm{CC}$ and CC:CSG remained more resistant to the detrimental effects of hydrogen ions and pepsin from the gastric fluids. Similarly, bile salts present in the SIJ affect the living cells by disrupting the structure and integrity of the cell membrane, thereby triggering the DNA damage and decreasing survival rate of free cells (Sannasiddappa et al., 2017). Very similar findings were recently reported for Lactobacillus reuteri encapsulated in gelatin/casein mixture which displayed significantly higher resistance against the bactericidal effect of SGJ and intestinal juice compared with cell encapsulated in casein or gelatin alone (Zhao et al., 2020). It was concluded that the protection efficiency of the microcapsules of Lactobacillus reuteri subjected to SGID, thermal treatment, and ambient storage always followed the following order: gelatin-casein $\geq$ casein $>$ gelatin-gum arabic $>$ gelatin (Zhao et al., 2020). Guimarães et al. (2013) also reported that free cells of L. rhamnosus and Bifidobacterium animalis failed to survive at low pH 2.0 and 2.5 after 180 min in SGF, whereas encapsulated cells in Ca-alginate beads showed the viability of 3.4 and $5.7 \log \mathrm{cfu} / \mathrm{g}$, respectively, at $\mathrm{pH}$ 2.0. Moreover, recent report on Lactobacillus acidophilus La-14 encapsulation in SA and bovine whey proteins revealed that only $33.41 \%$ of free cells were able to survive, whereas encapsulation in multiple layer alginate-whey matrix resulted in $77.45 \%$ viability of encapsulated cells upon their transit through SGID 
(de Araújo Etchepare et al., 2020). Alginate, pectin and gelatin-based microencapsulation of $L$. plantarum strain also reported to increase the cell viability by $90.02 \%$ (Vaziri et al., 2018). Furthermore, SA as wall material for probiotics, has certain limitations such as encapsulant leaching and burst release or rapid dissolution in the intestinal $\mathrm{pH}$ and in the presence of sodium ions (Fathi et al., 2014). Various studies reported that casein proteins have sponge-like structure with more internal cavities connected to each other, which offer better EE for probiotic cells (Tavares et al., 2014). Gelatin is amphoteric in nature with better crosslinking activity and hence efficient encapsulation of probiotic strains and protect them from the harsh environment in gastrointestinal conditions (Paula et al., 2019). These results suggest that $\mathrm{CC}$ and $\mathrm{CC}: \mathrm{CSG}$ had a better protective effect than SA alone on cell viability when exposed to the harsh conditions of SGID.

\section{Thermal Tolerance of the Encapsulated Probiotic Strains}

Studies suggest that extreme temperature beyond $65^{\circ} \mathrm{C}$ are highly damaging to probiotic cells due to the thermal stress. Microencapsulation is recommended to shield the probiotics as it can reduce the heat transfer from the surrounding medium to the cell interiors (Ahmad et al., 2019b).

Pasteurization is a common thermal process applied to many types of food and beverages. The viability of free and encapsulated probiotics before and after heating at $50^{\circ} \mathrm{C}$ and $70^{\circ} \mathrm{C}$ for 15 min was therefore monitored. Encapsulation of L. rhamnosus, P. pentosaceus, and L. paracasei within SA, CC, CSG, and CC:CSG exhibited significant differences in the cell viability when exposed to different levels of thermal treatment (Table 1 ). Free cells of $L$. rhamnosus were not able to survive the high temperature treatments at all, thus showing zero $\log \mathrm{cfu} / \mathrm{mL}$. However, upon encapsulation in different wall materials survival of probiotic cells displayed a significant increase. Overall, CC and CC:CSG encapsulation of L. rhamnosus were found to be more protective than SA and CSG alone. Free cells of $P$. pentosaceus showed survival of 5.47 and $4.51 \log \mathrm{cfu} / \mathrm{g}$ at 50 and $70^{\circ} \mathrm{C}$, respectively, wheras cells encapsulated in CC showed the highest viability (7.65 and $6.14 \mathrm{log} \mathrm{cfu} / \mathrm{g}$ ) after being exposed to both temperatures. Similar results were obtained for encapsulated cells of $P$. pentosaceus, where higher tolerance was exhibited in the presence of $\mathrm{CC}$ with 7.65 and $6.14 \log \mathrm{cfu} / \mathrm{g}$ at $50^{\circ} \mathrm{C}$ and $70^{\circ} \mathrm{C}$ respectively. Lowest survival was noticed for SA encapsulated cells with 6.87 and $5.28 \mathrm{log} \mathrm{cfu} / \mathrm{g}$ at $50^{\circ} \mathrm{C}$ and $70^{\circ} \mathrm{C}$. Furthermore,
L. paracasei encapsulated with $\mathrm{CC}$ was found to be highly tolerant toward heating even at $70^{\circ} \mathrm{C}$ for $15 \mathrm{~min}$ with $8.35 \mathrm{log} \mathrm{cfu} / \mathrm{g}$ of viable cells. On the contrary, SA encapsulated probiotics displayed lower survivability when subjected to gastrointestinal conditions compared with CC- and CSG-encapsulated probiotics, but at the same time it enhances the viability of probiotic cells at 50 and $70^{\circ} \mathrm{C}$. Zhao et al. (2020) have recently demonstrated that gelatin: casein complex was effective in providing higher thermal protection $\left(80^{\circ} \mathrm{C}\right.$ for $1 \mathrm{~h})$ to Lactobacillus reuteri cells when compared with gelatin and casein alone. The findings are consistent with several studies where encapsulated bacterial cells are more stable to heat treatment than the free cells (Ahmad et al., 2019b). Moreover, previous studies have shown that the alginate-gelatin microgels significantly enhanced the heat resistance of Lactobacillus salivarius (Li01) when compared with the alginate alone (Yao et al., 2017). Similarly, Yao et al. (2018) concluded that $P$. pentosaceus encapsulated in alginate-gelatin microgels showed the best heat tolerance at $63^{\circ} \mathrm{C}$ for 5 min with 7 to $8 \log \mathrm{cfu} / \mathrm{mL}$. Therefore, encapsulating probiotic cells in microcapsules prepared from CC and combination of CC and gelatin can be a more efficient strategy to enhance the thermal tolerance of the probiotic cells.

\section{Structural Characterization with FTIR Spectroscopy}

The FTIR spectrum were employed to determine the effect of encapsulating matrices on the molecular structure of the microcapsules encapsulating probiotic strains. The FTIR spectra for free cells of L. rhamnosus, $P$. pentosaceus, and L. paracasei and cell encapsulated in microcapsule prepared from SA-, CC-, CSG-, and CC:CSG-based wall materials are presented in Figure 1a-c. Careful observation of the FTIR spectra of free probiotic cells shows the distinct bands between 530 and $550 \mathrm{~cm}^{-1}$ corresponding to the characteristics of stretching and bending of the glycosidic bond COC (the bond that connects the 2 groups of sugars). $L$. paracasei and L. rhamnosus both showed a clear band at 857 and $870 \mathrm{~cm}^{-1}$ corresponding to $\mathrm{P}-\mathrm{O}$ bond from phosphorus present in the cell wall of bacteria (Figure 1a, c). Interestingly this band was not very prominent in $P$. pentosaceus strain possibly owing to differences in their cell wall composition (Figure 1b). Specific peaks at $1,236 \mathrm{~cm}^{-1}$ and $1,052 \mathrm{~cm}^{-1}$ relates to the phosphate stretch of the phosphodiester backbone of the nucleic acids (Lopes et al., 2017). In addition, all vibrations and stretching related to amide II and amide I were observed for all 3 probiotic strains in the range of 1,540 and $1,635 \mathrm{~cm}^{-1}$. The peak related to $\mathrm{C}-\mathrm{O}$ of carbonyl group in the ester linkages of fat molecules 
A)

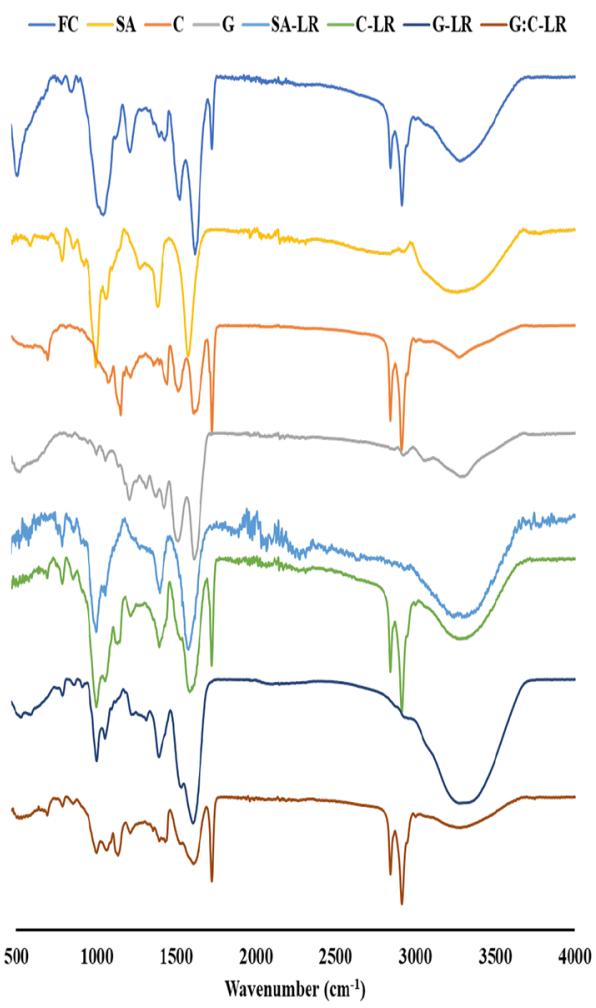

B)

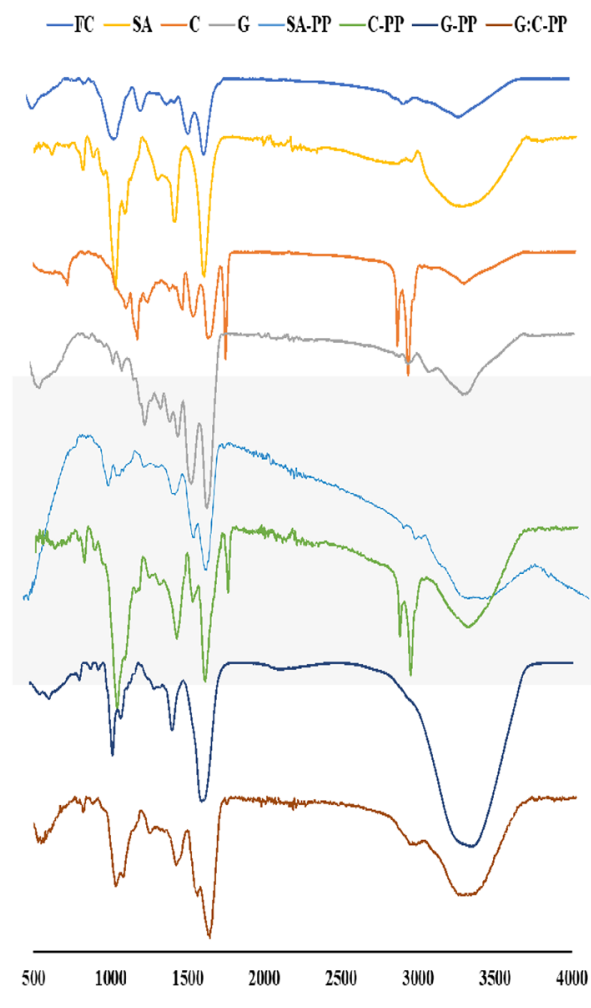

C)

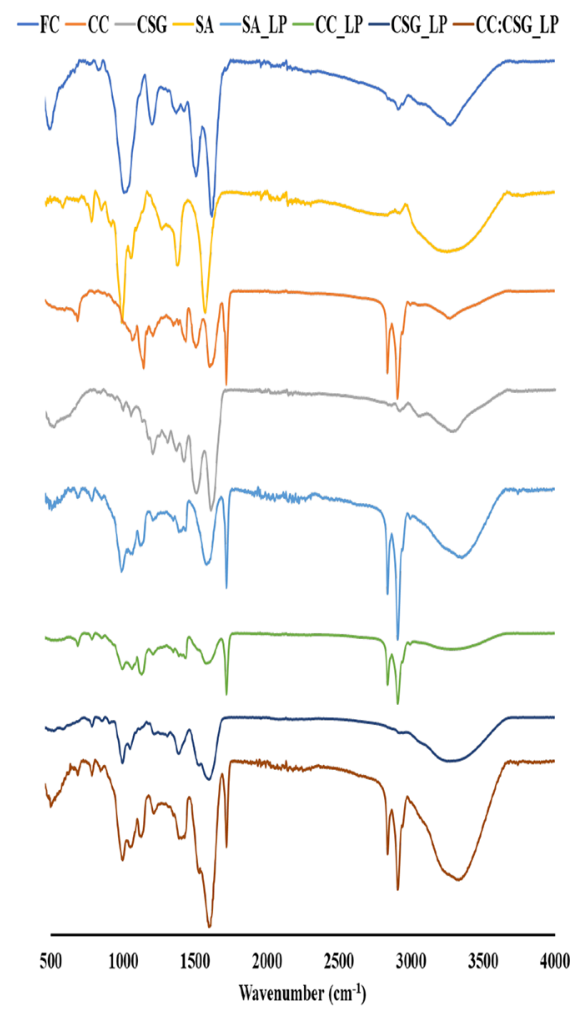

Figure 1. Fourier-transform infrared spectroscopy spectra of free cells (FC), and probiotic cells encapsulated in sodium alginate (SA), camel

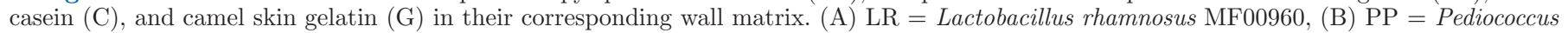
pentosaceus MF00096, and (C) LP = Lactobacillus paracasei DSM 20258.

and $\mathrm{CH}_{2}$ symmetric stretch were observed only in $L$. rhamnosus at $1,748 \mathrm{~cm}^{-1}$ and $2,852 \mathrm{~cm}^{-1}$, respectively.

The FTIR spectra of pure polysaccharide SA showed the peaks that correspond to major functional groups such as $\mathrm{OH}, \mathrm{CH}$, and monosaccharides. The wide absorption band obtained between 3,000 and $3,600 \mathrm{~cm}^{-1}$ is attributed to hydrogen bonds related stretching vibrations of hydroxyl groups The sharp peaks around $1,400 \mathrm{~cm}^{-1}$ and $1,600 \mathrm{~cm}^{-1}$ corresponded to symmetric and asymmetric stretching of carboxyl group as also explained by Vaziri et al. (2018). These bands are used as common distinguisher between alginate and its conjunction products (Daemi and Barikani, 2012). The peak at $1,026 \mathrm{~cm}^{-1}$ is related to $\mathrm{C}-\mathrm{O}-\mathrm{C}$ stretching from guluronic acid and the peak at $813 \mathrm{~cm}^{-1}$ is attributed to the $\mathrm{C}-\mathrm{O}$ stretching vibration of pyranosyl ring, with contributions from the deformation modes of $\mathrm{C}-\mathrm{C}-\mathrm{H}$ and $\mathrm{C}-\mathrm{O}-\mathrm{H}$ or $\mathrm{\alpha}$-configuration of the guluronic units.

The FTIR spectra gelatin protein displayed prominent amide I, II, and III as well as amide A and B peaks in the wave number ranged from 1,635 to $1,641 \mathrm{~cm}^{-1}$, $1,520.05$ to $1,560.0 \mathrm{~cm}^{-1}$, and 1,240 to $1,247 \mathrm{~cm}^{-1}$, respectively. Amide I vibration mode was primarily a
$\mathrm{C}=\mathrm{O}$ stretching coupled to contributions from the $\mathrm{C}-\mathrm{N}$ stretch, CCN deformation, and in-plane $\mathrm{N}-\mathrm{H}$ bending modes (Kittiphattanabawon et al., 2010). Amide II bands is usually caused by an out-of-phase combination of the $\mathrm{C}-\mathrm{N}$ group stretch vibration and $\mathrm{N}-\mathrm{H}$ group distortion modes of the peptide group (Nagarajan et al., 2012). Amide A peak detected at wavelengths ranging from 3,250 to $3,352 \mathrm{~cm}^{-1}$ corresponds to stretching vibration of the $\mathrm{N}-\mathrm{H}$ group linked with hydrogen bonding (Abuibaid et al., 2020). Similar, FTIR spectra for camel gelatin have been reported by Abuibaid et al. (2020). Observation of CCs through FTIR spectra revealed the presence of a characteristic band at $721 \mathrm{~cm}^{-1}$ which is attributed to $\mathrm{C}-\mathrm{C}$ or $\mathrm{N}-\mathrm{N}$ skeleton vibrations and served as the fingerprint band for casein protein (Socrates, 2004). Camel casein protein displayed a band around $1,098 \mathrm{~cm}^{-1}$ representing complex $\mathrm{C}-\mathrm{O}-\mathrm{C}$ ether stretching and symmetric $\mathrm{C}-\mathrm{H}$ deformation vibration, $1,170 \mathrm{~cm}^{-1}$ (C-H deformation vibration), $1,240 \mathrm{~cm}^{-1}$ (amide III group), 1,380 $\mathrm{cm}^{-1}$ (amide III bands), 1,465 $\mathrm{cm}^{-1}$ ( $\mathrm{CH}_{2}$ bending), $1,525 \mathrm{~cm}^{-1}$ (amide II group), $1,628 \mathrm{~cm}^{-1}$ (amide I group), $1,739 \mathrm{~cm}^{-1}(\mathrm{C}=\mathrm{O}$ stretching vibrations), $2,850 \mathrm{~cm}^{-1}$ (symmetric $\mathrm{C}-\mathrm{H}$ stretching 
vibration), $2,914 \mathrm{~cm}^{-1}$ (asymmetric $\mathrm{C}-\mathrm{H}$ stretching vibration) and $3,284 \mathrm{~cm}^{-1}(\mathrm{O}-\mathrm{H}$ stretching and $\mathrm{N}-\mathrm{H}$ stretching vibrations) were observed (Sarabandi et al., 2018).

Crosslinking of SA by calcium ion caused a shift in band at $1,301 \mathrm{~cm}^{-1}$ to $1,298,1,285$, and $1,238 \mathrm{~cm}^{-1}$ for L. rhamnosus, $P$. pentosaceus, and L. paracasei, respectively. The band at $1,407 \mathrm{~cm}^{-1}$ present in SA showed a shift in wavenumber to $1,420,1,476$ and $1,465 \mathrm{~cm}^{-1}$, respectively, for $L$. rhamnosus, P. pentosaceus, and $L$. paracase $i$, respectively. It is reported that shifting of peaks toward lower or higher wave numbers usually happen through intermolecular hydrogen bonding and electrostatic force interaction among the participating groups such as $\mathrm{O}-\mathrm{H}, \mathrm{N}-\mathrm{H}$, and $\mathrm{CO}$. These interactions could form and shorten the bond length of the $-\mathrm{NH}$ functional groups, thus increasing the wavenumbers. This indicates that alginate and probiotic cells formed intermolecular hydrogen bonding and electrostatic force interactions. Moreover, some studies related these shifts to the uniform placement of core structures (probiotics or bioactive) within the coating material such as caseins (Sarabandi et al., 2018). Meanwhile, a new narrower peak at $2,873 \mathrm{~cm}^{-1}$ in $P$. pentosaceus and 2 sharp peaks at 2,853 and $2,900 \mathrm{~cm}^{-1}$ for $L$. paracasei were observed. These new peaks in FTIR spectra of probiotics encapsulated in SA are attributed to the addition of $\mathrm{C}=\mathrm{O}$ stretching vibrations and symmetric $\mathrm{C}-\mathrm{H}$ stretching vibration generated from probiotic.

Moreover, the peaks for probiotics encapsulated in $\mathrm{CC}$ also showed he similar changes as were observed for probiotics encapsulated in SA. The presence of peaks in the region close to $880 \mathrm{~cm}^{-1}$, which is a fingerprint region for probiotics attributed to the $\mathrm{P}-\mathrm{O}$ bond from phosphorus confirmed the embedding of probiotics within casein matrix. In addition, the sole presence of peaks in region closer to $1,025 \mathrm{~cm}^{-1}$ indicated the presence of $\mathrm{C}-\mathrm{O}$ stretching vibration arising due to saturated aliphatic esters present in the cell membrane of microorganism. Similar observations were also noticed for cells encapsulated within CSG and CC:CSG matrix. Additionally, the encapsulation of probiotic cells in CSG alone led to the development of small new peaks in the region of $620-630 \mathrm{~cm}^{-1}$ and for both CSG- and CC:CSG-based encapsulation new peaks were observed in the region spanning 815 to $820 \mathrm{~cm}^{-1}$. These changes can be because of the effect of placement and distribution of probiotics and probably some of the hydrogen bonds between them. Overall, CC- and CSG-encapsulated probiotic strains exhibited the amide bands with varying intensity, which could be attributed to the hydrogen bonding with the dehydrated protein owing to freeze-drying with no significant change in the skeletal conformation. These findings provide evidence that SA, CC, CSG, and CC:CSG were proficient in encapsulating the probiotics bacteria with no significant change in their structural conformation.

\section{Microstructural Features}

Scanning electron microscopic observations of the surface characteristics of different microparticles encapsulating probiotic strains are presented in Figures 2,3 , and 4 . Micrographs of the free cells displayed the characteristic shape of the bacterial cells (rod-shaped and cocci-shaped or spherical) for all 3 probiotics used (Huang et al., 2018; Martin et al., 2019; Jiang et al., 2021). Pediococcus pentosaceus appeared to be in cluster of tetrads attach to each other with smooth surface morphologies, whereas L. rhamnosus and L. paracasei appeared as rod-shaped cells clustered together in chains (Figures 2 and 4, respectively). Entrapment of probiotic cells in different wall material led to change in their microstructural characteristics. The encapsulated $P$. pentosaceus cells were seen embedded inside the wall materials and were visible as small round particles in the different coating material (Figure 3). Furthermore, the surface of particle prepared with SA and CSG appeared to be more porous than the ones prepared with $\mathrm{CC}$ and combination of CC:CSG. Similar results were also obtained by Prasanna and Charalampopoulos (2018) where entrapment of Bifidobacterium longum inside SA microcapsules revealed presence of more porous structure than those obtained by mixture of SA and bovine and goat milk proteins. The less porous structure obtained with CC and CC: CSG might explain higher viability of entrapped bacteria in these capsules as microcapsules with cracks or more voids on their surface do not provide much protection to entrapped probiotics cells from adverse environmental conditions of freeze-drying and SGID. The microstructural images obtained for the CC and CGS matrices were similar to the previous reports that represented uniformly distributed probiotic strains within the interconnected protein matrices (Heidebach et al., 2010). Several studies also concluded that freezedrying resulted in shrunken and wrinkled matrices with rough surfaces and low porosity, which is in line with our current findings (Ptiček Siročić et al., 2016). Camel skin gelatin alone or in combination with CC displayed a microstructure consisting of crosslinked protein network somehow close to the microstructure of gelatin gels. To sum up, CC and CC:CSG offered structural integrity and rigidity as encapsulating matrices for probiotics which correlate with viability and bacterial cell death data. 


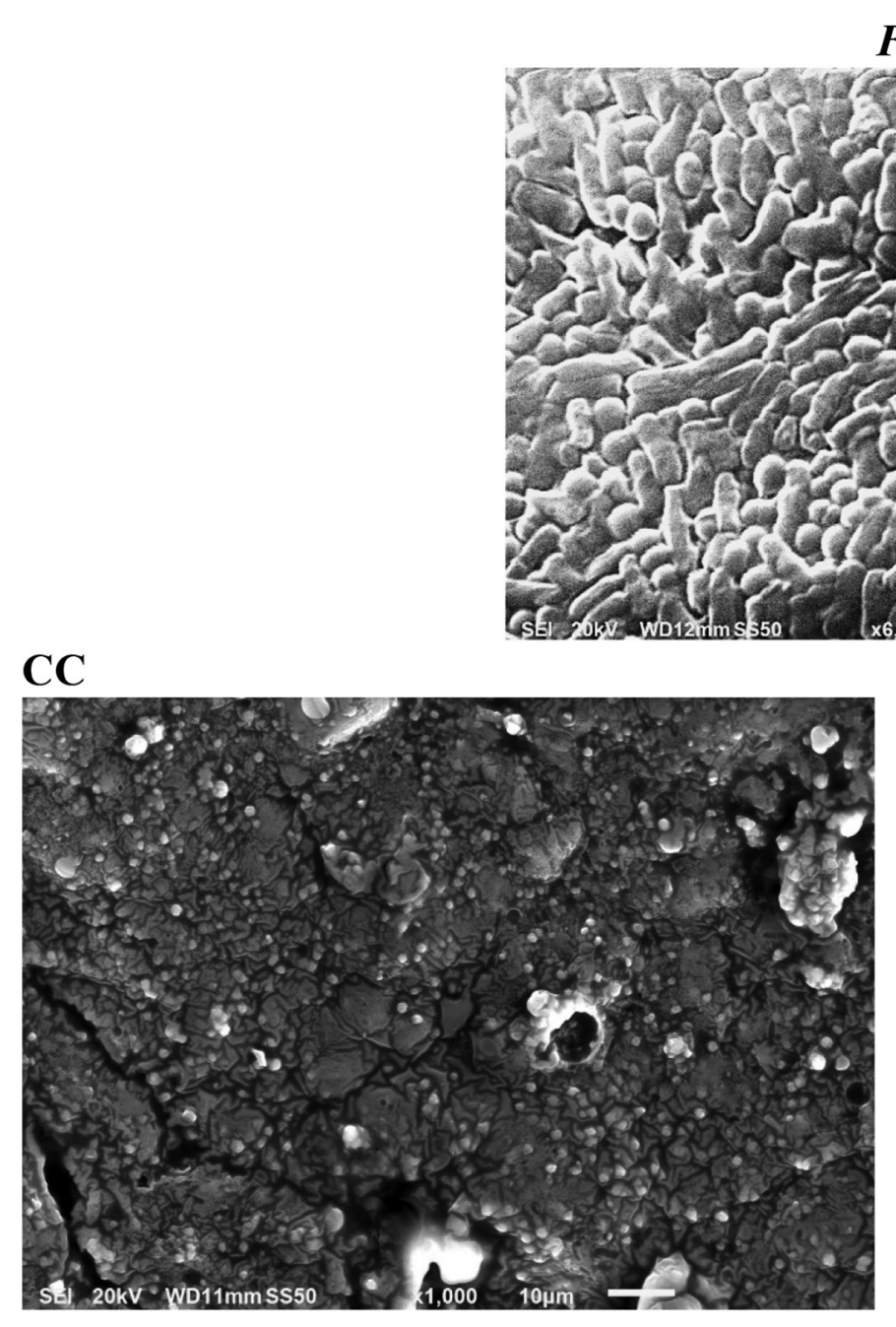

$F C$

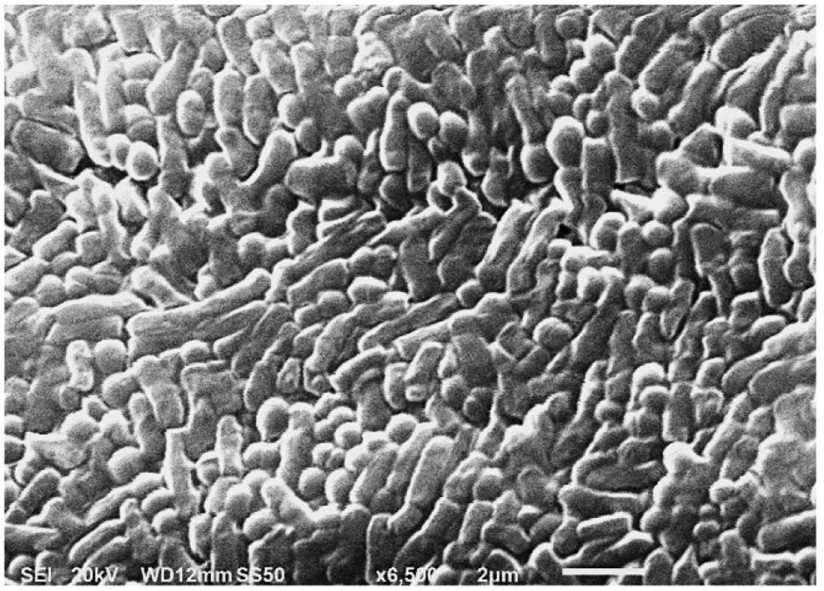

CSG

\section{CC: CSG}
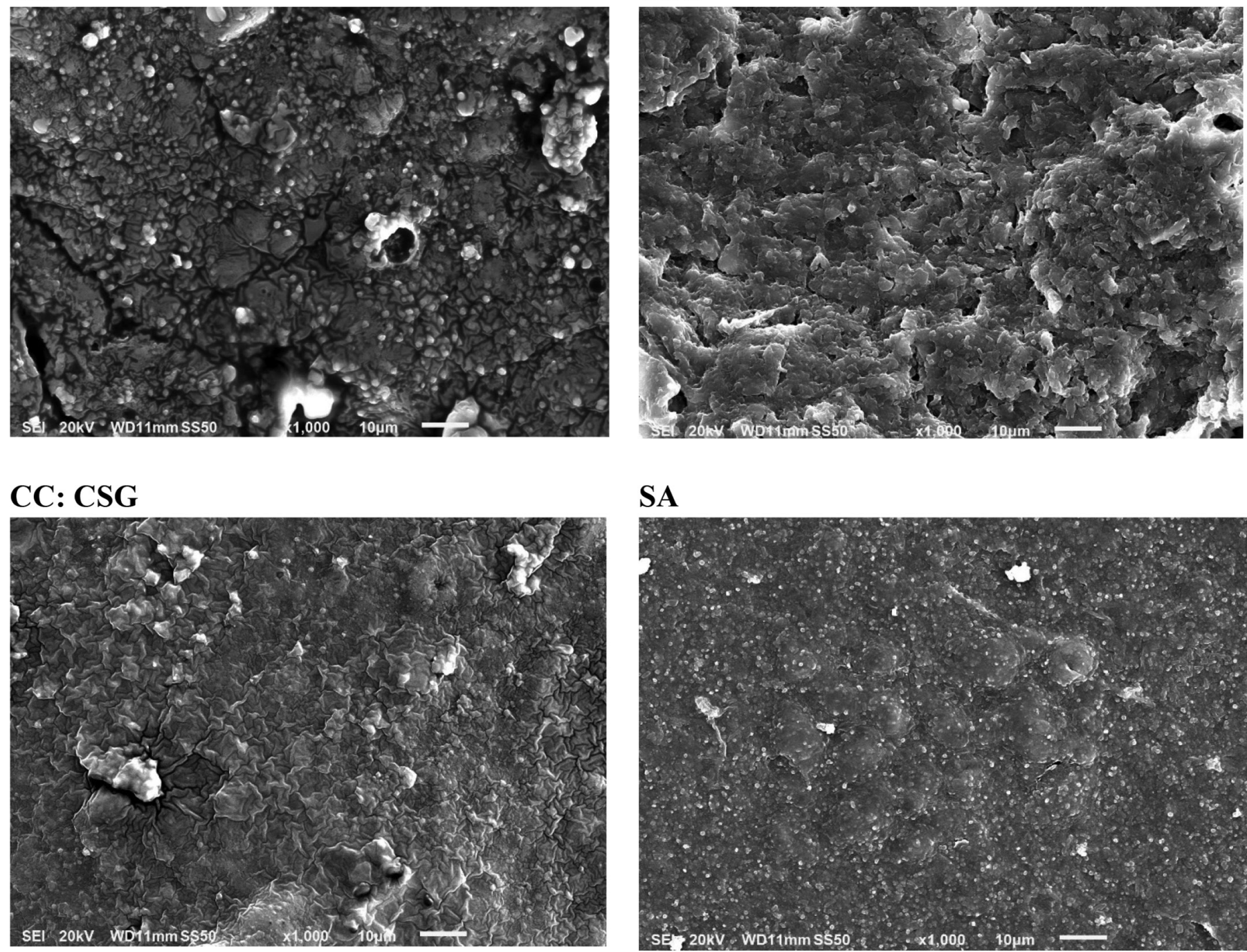

\section{SA}

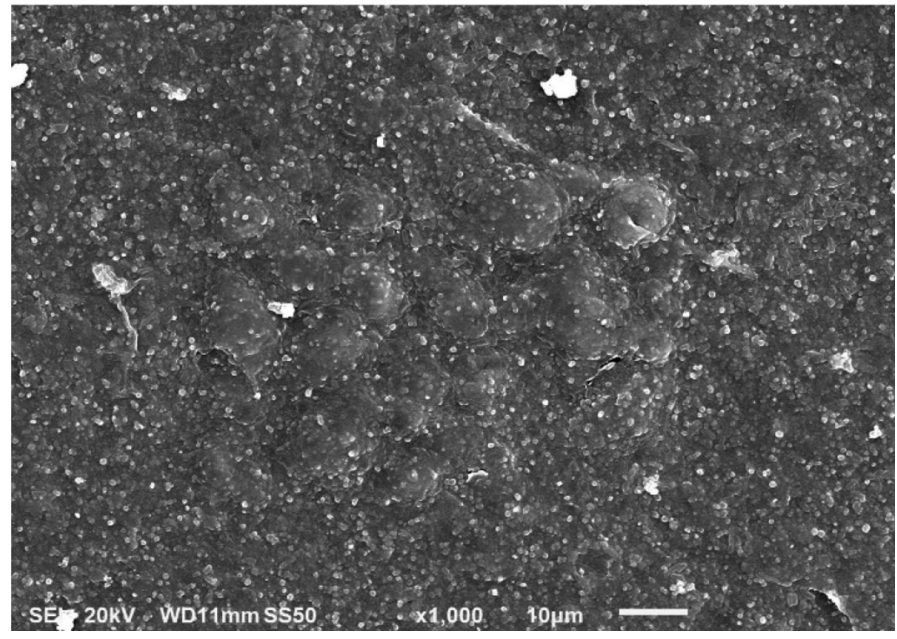

Figure 2. Scanning electron micrographs of Lactobacillus rhamnosus MF00960 as free cells (FC) or encapsulated in camel casein (CC), camel skin gelatin (CSG), CC:CSG (1:1 wt/wt), and sodium alginate (SA). 


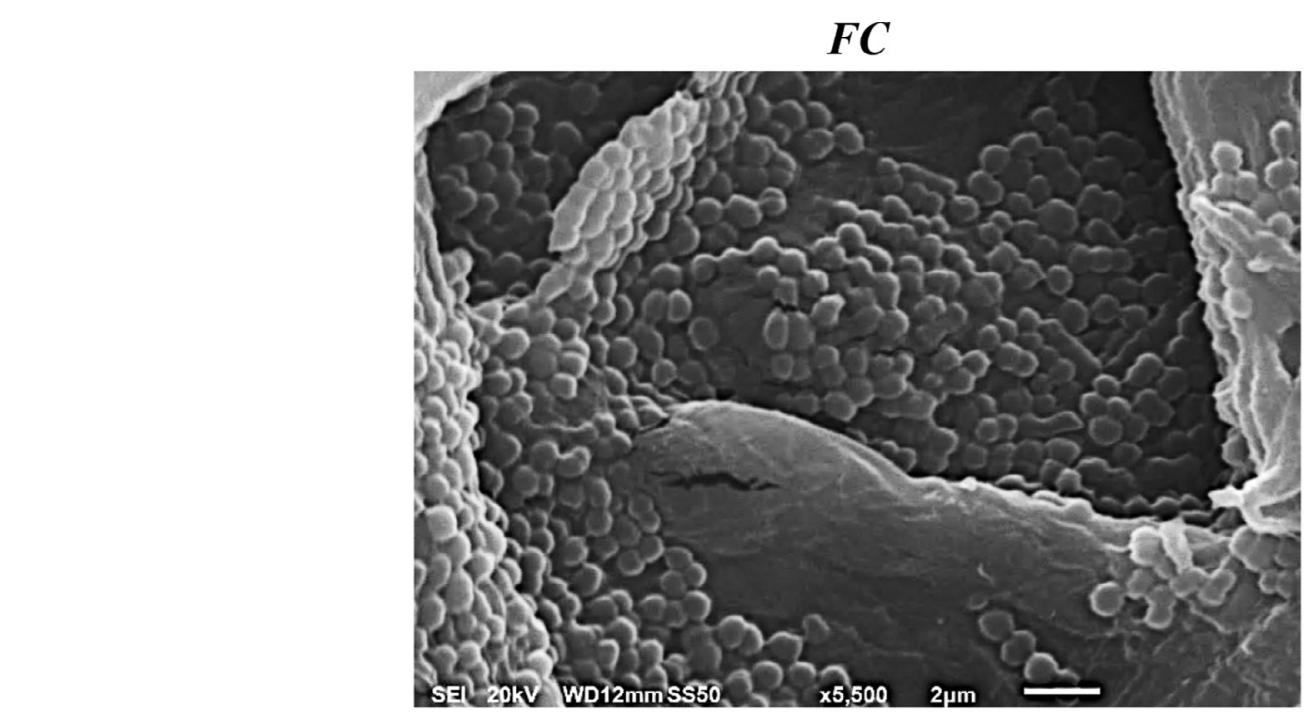

CC

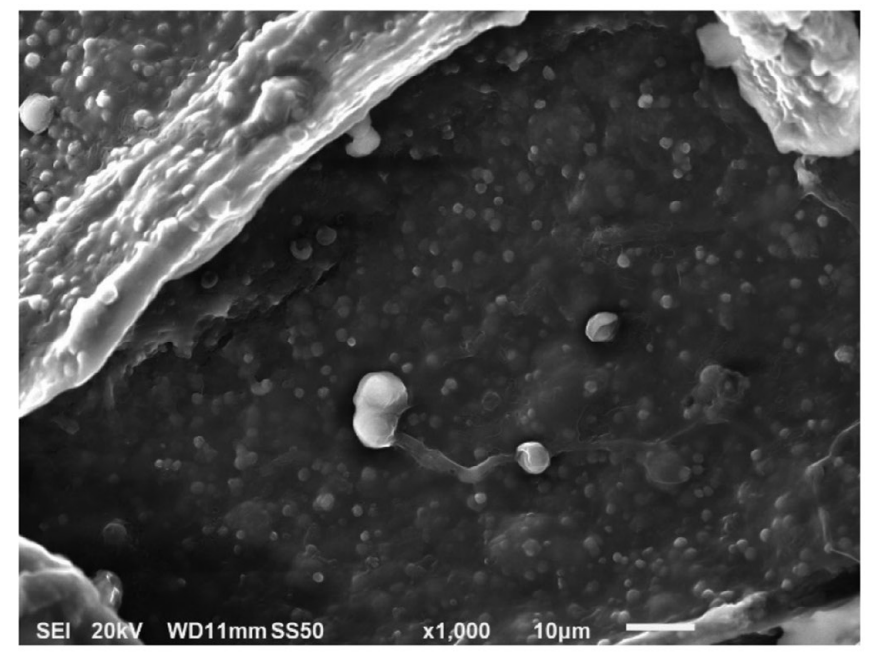

\section{CSG}

\section{$\mathrm{CC}: \mathrm{CSG}$}

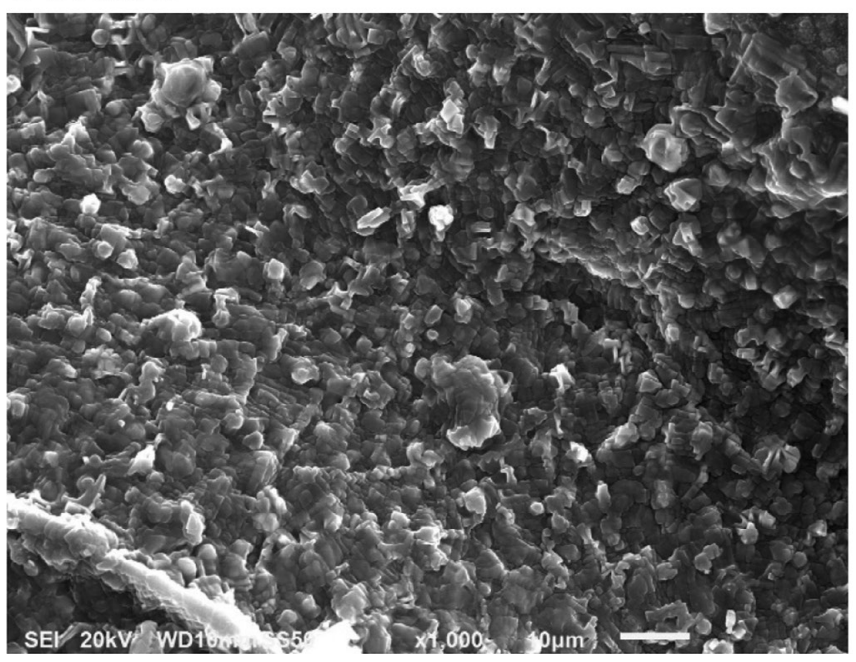

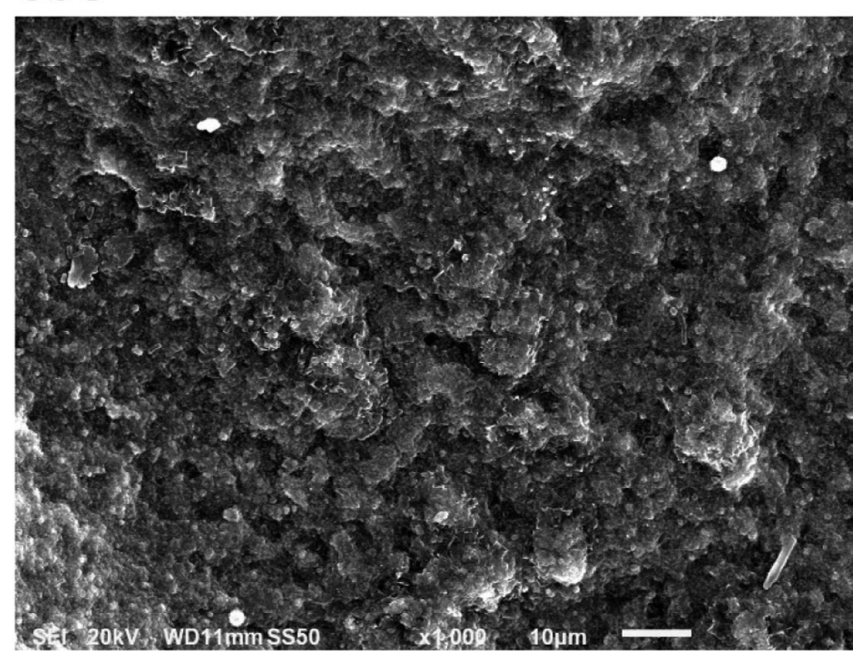

SA

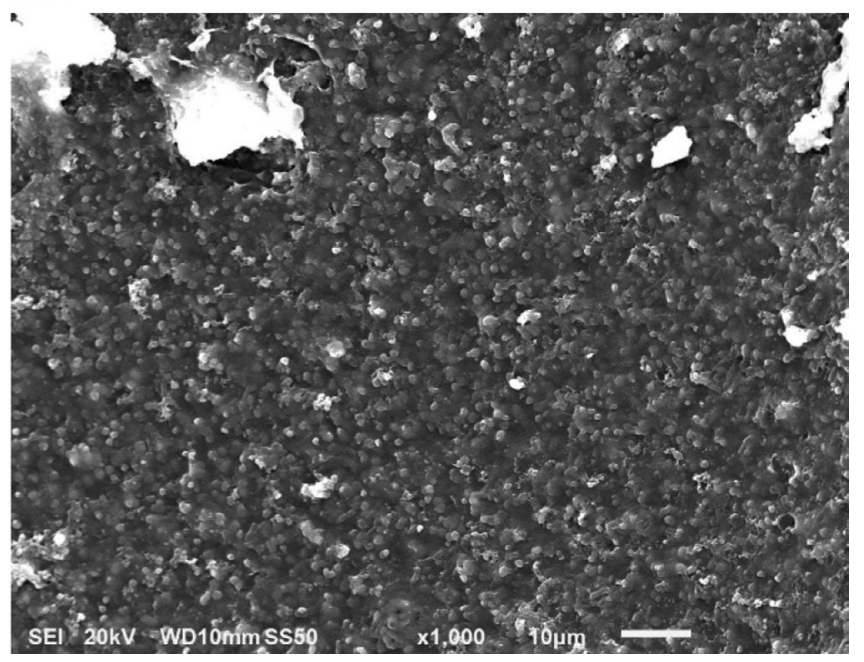

Figure 3. Scanning electron micrographs of Pediococcus pentosaceus MF00096 as free cells (FC) or encapsulated in camel casein (CC), camel skin gelatin (CSG), CC:CSG (1:1 wt/wt), and sodium alginate (SA). 


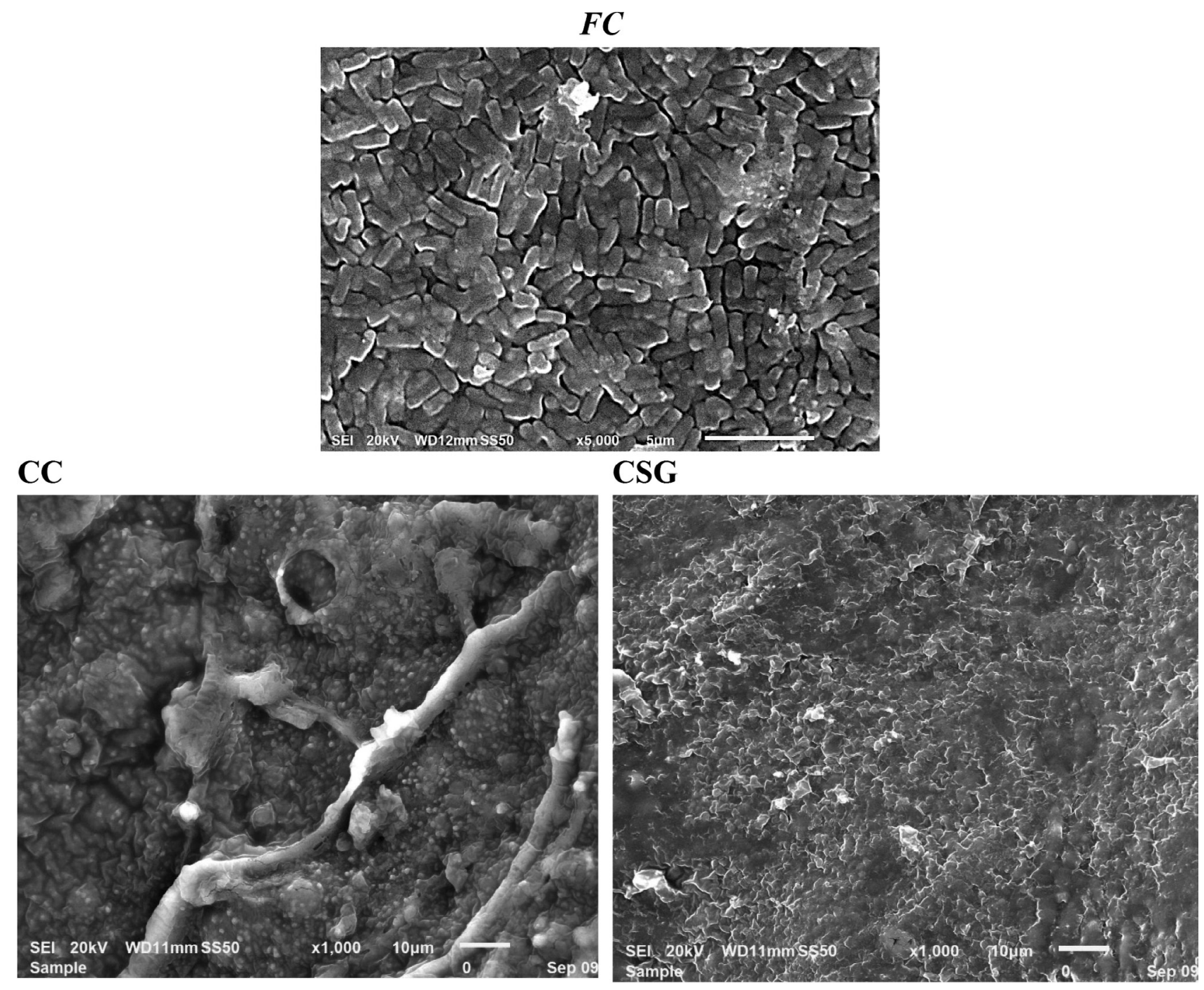

\section{CC:CSG}

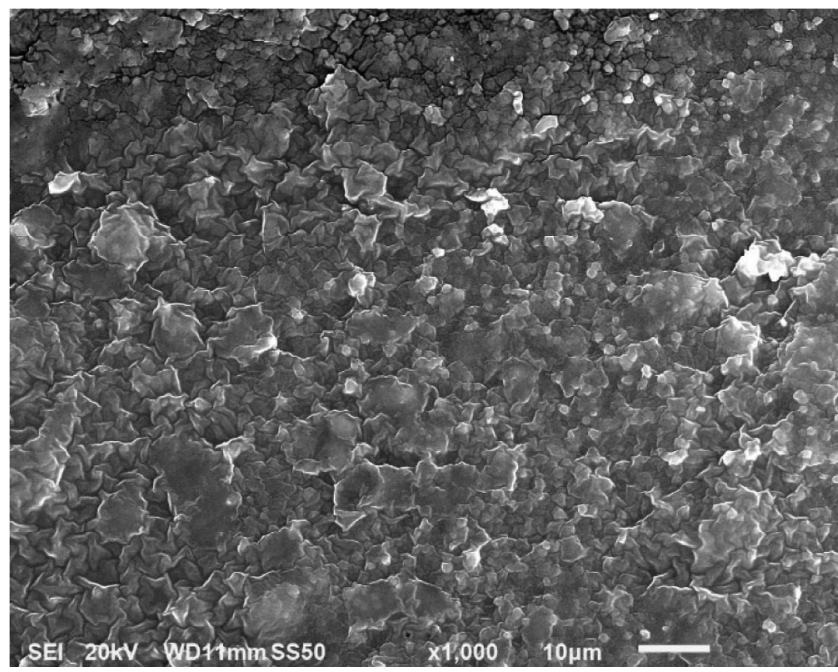

\section{SA}

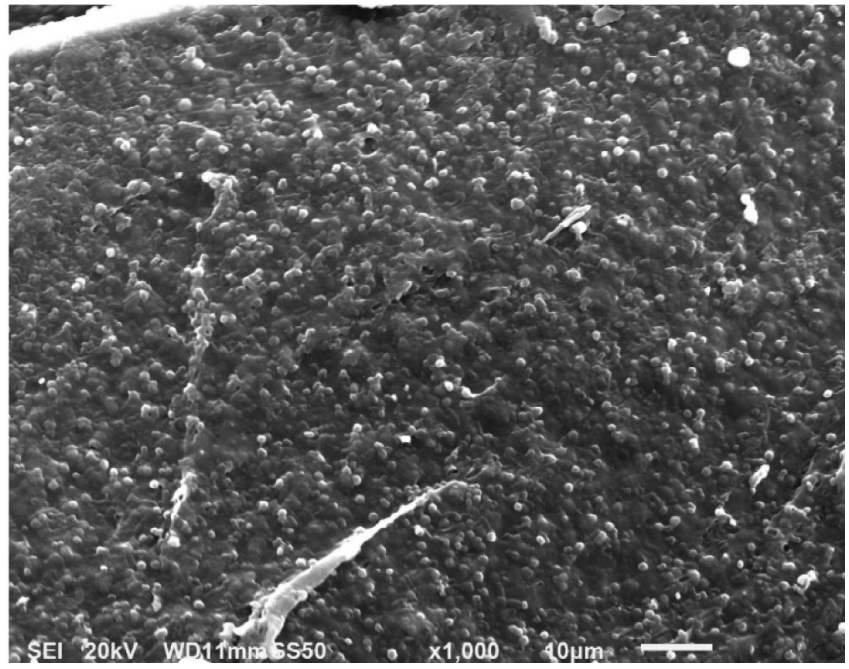

Figure 4. Scanning electron micrographs of Lactobacillus paracasei DSM 20258 as free cells (FC) or encapsulated in camel casein (CC), camel skin gelatin (CSG), CC:CSG (1:1 wt/wt), and sodium alginate (SA). 


\section{Effect of SGID on the Bioactive Properties of Free Cells and Encapsulated Probiotic Cells}

Inhibition of carbohydrate-hydrolyzing enzymes such as AG and PAA aids in managing type II diabetes by decreasing postprandial hyperglycemia. Similarly, inhibition of enzyme DPP-IV involved in degradation of incretin hormones is also advocated (Ashraf et al., 2021; Mudgil et al., 2021). Previous work also suggested that inhibitors of obesity-related enzymatic markers such as $\mathrm{PL}$ and $\mathrm{CE}$ are among the important therapeutic measure to manage complications associated with obesity (Mudgil et al., 2018; Ahmad et al., 2019a,b). Some previous reports suggested that cell-free extracts obtained from probiotic organisms possess inhibitory activity against AG, PAA, and DPP-IV, predicting this as one of the key mechanisms of action for their antidiabetic properties. The study conducted by Zeng et al. (2016a) showed that exopolysaccharides in the cell-free excretory supernatant of $L$. rhamnosus and $L$. paracase $i$ showed 27.6 and $28.3 \%$ of inhibitory potential against AG, respectively. Similarly, Panwar et al. (2016) also reported that Lactobacilli showed an inhibition of DPP-IV in the range of 20 to $80 \%$. Overall, to the best of our knowledge limited studies are available in this direction and warrants further exploration.

The inhibitory activities against enzyme related to complication of diabetes and obesity for all 3 probiotics, before and after SGID under free cells and encapsulated conditions are presented in Table 2 . The results showed that inhibition for AG displayed by the free probiotic cells before SGID transit were 85.43, 67.15, and 78.03\% for $L$. rhamnosus, P. pentosaceus, and L. paracasei, respectively. When free probiotics cells were subjected to the gastrointestinal conditions, AG inhibitory activity declined for all the probiotic strains with levels reaching up to $32.53,30.21$, and $56.01 \%$ for L. rhamnosus, P. pentosaceus, and L. paracasei, respectively. However, probiotic strains within the encapsulating matrices $\mathrm{CC}$ and CC:CSG contributed positively toward retention of the inhibitory activity of AG upon their transit through the gastrointestinal tract, and displayed higher AG inhibitory activities compared with free probiotic cells subjected to SGID $(P<0.05)$ (Table 2$)$. Similar results were obtained for PAA inhibitory activities of all 3 strains of probiotics. Before the gastrointestinal transit AG inhibition, varied between 58.86 and $73.03 \%$ with L. paracasei $(73.03 \%)$ being the most proactive probiotic followed by L. rhamnosus $(63.91 \%)$ and $P$. pentosaceus (58.86\%; Table 2). Upon SGID transit, the PAA inhibitory properties of all the probiotic strains declined with maximum reduction observed for $L$. rhamnosus where it nearly disappeared. However, encapsulation of probiotic strains within $\mathrm{CC}$ enhanced the PAA inhibitory potential of probiotics upon gastrointestinal transit, when compared with the free cells

Table 2. Effect of encapsulation on the retention of bioactivity of 3 probiotic strains upon in vitro simulated gastrointestinal digestion (SGID) ${ }^{1}$

\begin{tabular}{|c|c|c|c|c|c|}
\hline Parameter $^{2}$ & $\mathrm{AG}$ & PAA & DPP-4 & $\mathrm{PL}$ & $\mathrm{CE}$ \\
\hline \multicolumn{6}{|c|}{ Lactobacillus rhamnosus MF00960 } \\
\hline FC_NoSGID & $85.43 \pm 0.76^{\mathrm{d}}$ & $63.91 \pm 3.01^{\mathrm{d}}$ & $70.1 \pm 3.72^{\mathrm{c}}$ & $64.49 \pm 3.09^{\mathrm{e}}$ & $48.00 \pm 2.84^{\mathrm{bc}}$ \\
\hline FC_SGID & $32.53 \pm 1.36^{\mathrm{a}}$ & $1.00 \pm 0.32^{\mathrm{a}}$ & ND & $15.00 \pm 2.89^{\mathrm{a}}$ & $27.39 \pm 1.92^{\mathrm{a}}$ \\
\hline EC_SA & $61.13 \pm 0.68^{\mathrm{b}}$ & $46.95 \pm 2.16^{\mathrm{c}}$ & $30.58 \pm 2.15^{\mathrm{a}}$ & $46.52 \pm 1.00^{\mathrm{d}}$ & $46.35 \pm 2.42^{\mathrm{b}}$ \\
\hline EC_CC & $69.27 \pm 0.24^{\mathrm{c}}$ & $52.25 \pm 1.97^{\mathrm{c}}$ & $53.37 \pm 0.15^{\mathrm{b}}$ & $44.05 \pm 3.84^{\mathrm{cd}}$ & $53.10 \pm 0.68^{\mathrm{c}}$ \\
\hline EC_CSG & $62.16 \pm 2.31^{\mathrm{b}}$ & $36.55 \pm 2.79^{\mathrm{b}}$ & $30.58 \pm 2.15^{\mathrm{a}}$ & $25.70 \pm 2.32^{\mathrm{b}}$ & $47.90 \pm 3.03^{\mathrm{bc}}$ \\
\hline EC_CC:CSG (1:1 wt/wt) & $85.43 \pm 0.76^{\mathrm{d}}$ & $52.11 \pm 2.59^{\mathrm{c}}$ & $48.69 \pm 0.55^{\mathrm{b}}$ & $37.63 \pm 1.21^{\mathrm{c}}$ & $54.13 \pm 2.31^{\mathrm{c}}$ \\
\hline \multicolumn{6}{|c|}{ Pediococcus pentosaceus MF000967 } \\
\hline FC_NoSGID & $67.15 \pm 0.93^{\mathrm{e}}$ & $58.86 \pm 0.78^{\mathrm{b}}$ & $43.74 \pm 0.6^{\mathrm{c}}$ & $53.24 \pm 0.99^{\mathrm{c}}$ & $64.03 \pm 0.72^{\mathrm{e}}$ \\
\hline FC_SGID & $30.21 \pm 1.19^{\mathrm{a}}$ & $44.66 \pm 0.59^{\mathrm{a}}$ & $27.66 \pm 0.3^{\mathrm{a}}$ & $12.9 \pm 0.84^{\mathrm{a}}$ & $32.24 \pm 0.36^{\mathrm{a}}$ \\
\hline EC_SA & $43.39 \pm 0.21^{\mathrm{c}}$ & $69.96 \pm 0.18^{\mathrm{d}}$ & $34.62 \pm 0.46^{\mathrm{b}}$ & $41.64 \pm 0.5^{\mathrm{b}}$ & $49.47 \pm 0.4^{\mathrm{d}}$ \\
\hline EC_CC & $49.1 \pm 0.12^{\mathrm{d}}$ & $79.34 \pm 0.1^{\mathrm{f}}$ & $65.94 \pm 0.9^{\mathrm{e}}$ & $71.52 \pm 0.18^{\mathrm{d}}$ & $49.56 \pm 1.03^{\mathrm{d}}$ \\
\hline EC_CSG & $35.89 \pm 0.15^{\mathrm{b}}$ & $63.06 \pm 0.16^{\mathrm{c}}$ & $29.21 \pm 0.61^{\mathrm{a}}$ & $40.83 \pm 0.88^{\mathrm{b}}$ & $40.85 \pm 0.12^{\mathrm{b}}$ \\
\hline EC_CC:CSG (1:1 wt/wt) & $41.67 \pm 0.96^{\mathrm{c}}$ & $71.14 \pm 0.03^{\mathrm{e}}$ & $47.03 \pm 0.99^{\mathrm{d}}$ & $71.4 \pm 0.12^{\mathrm{d}}$ & $45.81 \pm 1.32^{\mathrm{c}}$ \\
\hline \multicolumn{6}{|c|}{ Lactobacillus paracasei DSM 20258} \\
\hline FC_NoSGID & $78.03 \pm 1.03^{\mathrm{c}}$ & $73.03 \pm 0.79^{\mathrm{b}}$ & $48.69 \pm 0.55^{\mathrm{d}}$ & $67.91 \pm 0.35^{\mathrm{d}}$ & $56.88 \pm 1.45^{\mathrm{d}}$ \\
\hline $\mathrm{FC} \_\mathrm{SGID}$ & $56.01 \pm 0.94^{\mathrm{a}}$ & $52.3 \pm 0.41^{\mathrm{a}}$ & $7.692 \pm 0.31^{\mathrm{a}}$ & $42.28 \pm 1.58^{\mathrm{a}}$ & $18.13 \pm 0.42^{\mathrm{a}}$ \\
\hline EC_SA & $71.76 \pm 0.54^{\mathrm{b}}$ & $52.19 \pm 4.76^{\mathrm{a}}$ & $45.96 \pm 0.78^{\mathrm{c}}$ & $65.17 \pm 0.67^{\mathrm{c}}$ & $38.41 \pm 0.24^{\mathrm{b}}$ \\
\hline EC_CC & $81.99 \pm 0.43^{\mathrm{d}}$ & $91.33 \pm 2.98^{\mathrm{d}}$ & $50.59 \pm 0.07^{\mathrm{e}}$ & $55.01 \pm 0.79^{\mathrm{b}}$ & $50.83 \pm 0.37^{\mathrm{c}}$ \\
\hline EC_CSG & $73.59 \pm 0.21^{\mathrm{b}}$ & $81.51 \pm 3.62^{\mathrm{c}}$ & $25.24 \pm 0.81^{\mathrm{b}}$ & $54.27 \pm 0.29^{\mathrm{b}}$ & $57.88 \pm 2.55^{\mathrm{d}}$ \\
\hline EC_CC:CSG (1:1 wt/wt) & $81.61 \pm 1.03^{\mathrm{d}}$ & $77.04 \pm 1.02^{\mathrm{bc}}$ & $66.13 \pm 0.71^{\mathrm{f}}$ & $76.07 \pm 0.58^{\mathrm{e}}$ & $64.66 \pm 0.06^{\mathrm{e}}$ \\
\hline
\end{tabular}

\footnotetext{
${ }^{\mathrm{a}-\mathrm{f}}$ Means with different letters in a column represent significant difference $(P<0.05)$ between different samples within each probiotic strain.

${ }^{1}$ Results are represented as percent inhibition of $\alpha$-Glucosidase (AG), pancreatic $\alpha$-amylase (PAA), Dipeptidyl peptidase (DPP-IV), Porcine pancreatic lipase (PPL), and cholesteryl esterase (CE). Data expressed as mean \pm SD $(n=3)$. ND = not detected (no inhibitory activity detected).

${ }^{2} \mathrm{FC}=$ free cells; $\mathrm{EC}=$ encapsulated cells, $\mathrm{SA}=$ sodium alginate $\mathrm{CC}=$ camel casein $; \mathrm{CSG}=$ camel skin gelatin; $\mathrm{CC}: \mathrm{CGS}=1: 1 \mathrm{wt} / \mathrm{wt}$ encapsulated probiotic strains.
} 
subjected to SGID $(P<0.05)$. Among 3 strains, higher retention of the PAA inhibitory activity were observed for encapsulated $P$. pentosaceus in all wall matrices, whereas for $L$. paracasei significant increase in PAA inhibitory activity was obtained for probiotics cells encapsulated in CC, CSG, and CC:CSG. In summary, encapsulated probiotic strains displayed better inhibitory activity toward AG and PAA and could serve as a dietary intervention in managing type II diabetes. The results obtained in this study corroborate well with previous reports of Ahmad et al. (2019b) where encapsulation of probiotic strain of $P$. acidilactici in bovine and camel whey proteins resulted in significant retainment of AG and PPA inhibitory properties.

With regards to DPP-IV inhibitory activity of the L. rhamnosus, P. pentosaceus, and L. paracasei, all the free probiotics cell showed varying levels of DPP-IV inhibitory activity, with $L$. rhamnosus $(70.1 \%)$ showing the highest activity, followed by L. paracasei (48.69\%) and P. pentosaceus (43.74\%). The results obtained corroborates those obtained from previous studies by Zeng et al. (2016a,b), who reported that Lactobacillus (7.2-33.3\%) and Bifidobacterium strains (7-27\%) possessed inhibitory activity against DPP-IV. Similarly, Panwar et al. (2016) also reported that different Lactobacillus isolates displayed different levels of inhibition against DPP-IV (10-32\%). In the present study, when different probiotic strains were exposed to the gastrointestinal conditions, DPP-IV inhibitory activity was not detected for L. rhamnosus, whereas 27.66 and $7.692 \%$ of inhibitory potential were observed with $P$. pentosaceus and L. paracasei, respectively. However, CC:CSG-encapsulated L. paracasei showed the greatest inhibitory potential (66.13\%) against DPP-IV, followed by CC-encapsulated P. pentosaceus (65.94\%) and L. rhamnosus $(53.37 \%)$ upon their transition through SGID (Table 2). These findings confirm the importance of probiotic encapsulation that could protect the beneficial bioactive properties.

Inhibition of PL reduces the efficiency of fat absorption in the small intestine resulting in the long-term reduction of BW. Similarly, CE plays a key role in regulating the plasma cholesterol concentration and inhibition of $\mathrm{CE}$ results in decreasing the levels of cholesterol (Jafar et al., 2018). Inhibition percentage displayed by the free probiotic strains (L. rhamnosus, $P$. pentosaceus, and L. paracasei) were $64.49,53.24$, and $67.91 \%$ for PPL and $48.00,64.03$, and $56.88 \%$ for CE, respectively. The trend suggests a decrease in PL and CE inhibitory activities when the free cells were subjected to the simulated digestion whereas encapsulation with SA, CC, CSG, and CC:CSG markedly retained the activities within varying levels. Overall, L. rhamnosus encapsulated in SA displayed higher PL inhibitory activity $(46.52 \%)$ followed by cells encapsulated in CC (44.05\%; P> 0.05), and for P. pentosaceus and L. paracasei highest PL inhibitory activity was demonstrated by cells encapsulated in CC:CSG with an inhibitory percentage of 71.4 and $76.07 \%$, respectively.

Thus, L. paracasei strain encapsulated with CC:CSG exhibited the highest inhibiting potential against PL and CE, whereas CC- and CC:CSG-encapsulated $P$. pentosaceus displayed higher levels of inhibitory activity against PL and CE (Table 2). This could be due to the encapsulating matrices protecting the probiotic strains from harsh conditions of SGID thereby retaining their inhibitory potential against PL and CE. Recently, Ahmad et al. (2019b) reported increased PL and CE inhibitory activity of $P$. acidilactici $\mathrm{S} 30-4 \mathrm{C}$ when encapsulated with bovine and camel whey protein.

The loss of enzyme inhibitory property by the probiotic strains upon SGID could be possibly attributed to the loss in viability and induced stress among cells that limited the production of inhibitory components by probiotic cells. Thus, it is suggested that encapsulation of cells within different wall matrices could maintain the high viability of the probiotic cells in addition to keeping their cell membrane intact and also protect the cells from external stress. These protections imparted by wall material matrix help probiotic cells in effectively producing inhibitors at a faster and higher level. It is also possible that the probiotic cells use different wall materials such as CC and CSG as nutrient substrate and degrade them, resulting in production of potent bioactive molecules which might also contribute to the enzyme inhibitory activities. More studies at molecular level are needed to gain deeper insight into the reasons behind these variation among probiotic cells before and after encapsulation.

\section{CONCLUSIONS}

This study demonstrated the survival and functionality of probiotic strains (L. rhamnosus, P. pentosaceus, and L. paracasei) encapsulated in SA and CC and CSG. The CC-based matrices were efficient in protecting the probiotic strains during freeze-drying and thermal treatment showing higher cell viability and survival compared with probiotics encapsulated in CSG and CC+CSG. Furthermore, probiotic strains encapsulated with CC and CC:CSG also displayed enhanced cell viability under simulated gastrointestinal conditions. Probiotic strains in the encapsulated form were also found to maintain or enhance the inhibitory properties against $\alpha$-glucosidase, $\alpha$-amylase, DPP-IV activity, pancreatic lipase, and cholesterol esterase, which supports the future investigation on probiotics as a functionally bioactive ingredients with specific health- 
promoting properties. However, it is still unclear and further work is necessary to understand the key mechanisms involved in maintaining these bioactivities by probiotics strains.

\section{ACKNOWLEDGMENTS}

The authors are grateful to United Arab Emirates University (Al-Ain, UAE) for funding this research through a research grant (Fund code-31R214 and 31F094) awarded to the principal investigator, Sajid Maqsood. The authors have not stated any conflicts of interest.

\section{REFERENCES}

Abd El-Salam, M. H., and S. El-Shibiny. 2015. Preparation and properties of milk proteins-based encapsulated probiotics: A review. Dairy Sci. Technol. 95:393-412. https://doi.org/10.1007/s13594 $-015-0223-8$.

Abuibaid, A., A. AlSenaani, F. Hamed, P. Kittiphattanabawon, and S. Maqsood. 2020. Microstructural, rheological, gel-forming and interfacial properties of camel skin gelatin. Food Struct. 26:100156. https://doi.org/10.1016/j.foostr.2020.100156.

Ahmad, M., P. Mudgil, A. Gani, F. Hamed, F. A. Masoodi, and S. Maqsood. 2019a. Nano-encapsulation of catechin in starch nanoparticles: Characterization, release behavior and bioactivity retention during simulated in vitro digestion. Food Chem. 270:95104. https://doi.org/10.1016/j.foodchem.2018.07.024.

Ahmad, M., P. Mudgil, and S. Maqsood. 2019b. Camel whey protein microparticles for safe and efficient delivery of novel camel milk derived probiotics. Lebensm. Wiss. Technol. 108:81-88. https:// doi.org/10.1016/j.lwt.2019.03.008.

Ajayi, F. F., P. Mudgil, C. Y. Gan, and S. Maqsood. 2021. Identification and characterization of cholesterol esterase and lipase inhibitory peptides from amaranth protein hydrolysates. Food Chem. X 12:100165. https://doi.org/10.1016/j.fochx.2021.100165.

Arslan, S., M. Erbas, I. Tontul, and A. Topuz. 2015. Microencapsulation of probiotic Saccharomyces cerevisiae var. boulardii with different wall materials by spray drying. Lebensm. Wiss. Technol. 63:685-690. https://doi.org/10.1016/j.lwt.2015.03.034.

Ashraf, A., P. Mudgil, A. Palakkott, R. Iratni, C. Y. Gan, S. Maqsood, and M. A. Ayoub. 2021. Molecular basis of the anti-diabetic properties of camel milk through profiling of its bioactive peptides on dipeptidyl peptidase IV (DPP-IV) and insulin receptor activity. J. Dairy Sci. 104:61-77. https://doi.org/10.3168/jds.2020-18627.

Burgain, J., C. Gaiani, C. Cailliez-Grimal, C. Jeandel, and J. Scher. 2013. Encapsulation of Lactobacillus rhamnosus $G G$ in microparticles: Influence of casein to whey protein ratio on bacterial survival during digestion. Innov. Food Sci. Emerg. Technol. 19:233-242. https://doi.org/10.1016/j.ifset.2013.04.012.

Daemi, H., and M. Barikani. 2012. Synthesis and characterization of calcium alginate nanoparticles, sodium homopolymannuronate salt and its calcium nanoparticles. Sci. Iran. 19:2023-2028. https:/ /doi.org/10.1016/j.scient.2012.10.005.

de Araújo Etchepare, M., G. L. Nunes, B. R. Nicoloso, J. S. Barin, E. M. Moraes Flores, R. de Oliveira Mello, and C. Ragagnin de Menezes. 2020. Improvement of the viability of encapsulated probiotics using whey proteins. Lebensm. Wiss. Technol. 117:108601. https:/ /doi.org/10.1016/j.lwt.2019.108601.

Fathi, M., A. Martin, and D. J. McClements. 2014. Nanoencapsulation of food ingredients using carbohydrate based delivery systems. Trends Food Sci. Technol. 39:18-39. https://doi.org/10.1016/j.tifs 2014.06.007.

Fawale, S. O., A. Abuibaid, F. Hamed, P. Kittiphattanabawon, and S. Maqsood. 2021. Molecular, structural, and rheological char- acterization of camel skin gelatin extracted using different pretreatment conditions. Foods 10:1563. https://doi.org/10.3390/ foods10071563.

Gu, M., Z. Zhang, C. Pan, T. R. Goulette, R. Zhang, G. Hendricks, D. J. McClements, and H. Xiao. 2019. Encapsulation of Bifidobacterium pseudocatenulatum G7 in gastroprotective microgels: Improvement of the bacterial viability under simulated gastrointestinal conditions. Food Hydrocoll. 91:283-289. https://doi.org/10.1016/ j.foodhyd.2019.01.040.

Guimarães, R. R., A. L. A. Vendramini, A. C. Santos, S. G. F. Leite, and M. A. L. Miguel. 2013. Development of probiotic beads similar to fish eggs. J. Funct. Foods 5:968-973. https://doi.org/10.1016/ j.jff.2013.01.002.

Haffner, F. B., R. Diab, and A. Pasc. 2016. Encapsulation of probiotics: Insights into academic and industrial approaches. AIMS Mater. Sci. 3:114-136. https://doi.org/10.3934/matersci.2016.1.114.

Heidebach, T., P. Först, and U. Kulozik. 2010. Influence of caseinbased microencapsulation on freeze-drying and storage of probiotic cells. J. Food Eng. 98:309-316. https://doi.org/10.1016/j.jfoodeng 2010.01 .003$.

Huang, C. H., S. W. Li, L. Huang, and K. Watanabe. 2018. Identification and classification for the Lactobacillus casei group. Front. Microbiol. 9:1974. https://doi.org/10.3389/fmicb.2018.01974.

Jafar, S., H. Kamal, P. Mudgil, H. M. Hassan, and S. Maqsood. 2018. Camel whey protein hydrolysates displayed enhanced cholesteryl esterase and lipase inhibitory, anti-hypertensive and anti-haemolytic properties. Lebensm. Wiss. Technol. 98:212-218. https://doi .org/10.1016/j.lwt.2018.08.024.

Jiang, N., G. Dev Kumar, J. Chen, A. Mishra, and K. Mis Solval. 2020. Comparison of concurrent and mixed-flow spray drying on viability, growth kinetics and biofilm formation of Lactobacillus rhamnosus GG microencapsulated with fish gelatin and maltodextrin. Lebensm. Wiss. Technol. 124:109200. https://doi.org/10 .1016/j.lwt.2020.109200.

Jiang, S., L. Cai, L. Lv, and L. Li. 2021. Pediococcus pentosaceus, a future additive or probiotic candidate. Microb. Cell Fact. 20:45 https://doi.org/10.1186/s12934-021-01537-y.

Kamal, H., S. Jafar, P. Mudgil, C. Murali, A. Amin, and S. Maqsood. 2018. Inhibitory properties of camel whey protein hydrolysates toward liver cancer cells, dipeptidyl peptidase-IV, and inflammation. J. Dairy Sci. 101:8711-8720. https://doi.org/10.3168/jds .2018-14586.

Kanmani, P., R. S. Kumar, N. Yuvaraj, K. Paari, V. Pattukumar, and V. Arul. 2011. Cryopreservation and microencapsulation of a probiotic in alginate-chitosan capsules improves survival in simulated gastrointestinal conditions. Biotechnol. Bioprocess Eng. 16:11061114. https://doi.org/10.1007/s12257-011-0068-9.

Khalil, K. A., S. Mustafa, R. Mohammad, A. B. Ariff, S. A. Ahmad, F. A. Dahalan, and M. Y. Abdul Manap. 2019. Encapsulation of Bifidobacterium pseudocatenulatum strain G4 within Bovine gelatingenipin-sodium alginate combinations: Optimisation approach using face central composition design-response surface methodology (FCCD-RSM). Int. J. Microbiol. 2019:4208986. https://doi.org/10 $1155 / 2019 / 4208986$

Kittiphattanabawon, P., S. Benjakul, W. Visessanguan, and F. Shahidi. 2010. Comparative study on characteristics of gelatin from the skins of brownbanded bamboo shark and blacktip shark as affected by extraction conditions. Food Hydrocoll. 24:164-171. https://doi .org/10.1016/j.foodhyd.2009.09.001.

Li, X. Y., X. G. Chen, D. S. Cha, H. J. Park, and C. S. Liu. 2009. Microencapsulation of a probiotic bacteria with alginate-gelatin and its properties. J. Microencapsul. 26:315-324. https://doi.org/ $10.1080 / 02652040802328685$.

Lian, W.-C., H.-C. Hsiao, and C.-C. Chou. 2003. Viability of microencapsulated bifidobacteria in simulated gastric juice and bile solution. Int. J. Food Microbiol. 86:293-301. https://doi.org/10.1016/ S0168-1605(02)00563-9.

Lopes, S., L. Bueno, F. D. E. Aguiar Jr., and C. Finkler. 2017. Preparation and characterization of alginate and gelatin microcapsules containing Lactobacillus rhamnosus. An. Acad. Bras. Cienc. 89:1601-1613. https://doi.org/10.1590/0001-3765201720170071. 
Martín, R., C. Chamignon, N. Mhedbi-Hajri, F. Chain, M. Derrien, U. Escribano-Vázquez, P. Garault, A. Cotillard, H. P. Pham, C. Chervaux, L. G. Bermúdez-Humarán, T. Smokvina, and P. Langella. 2019. The potential probiotic Lactobacillus rhamnosus CNCM I-3690 strain protects the intestinal barrier by stimulating both mucus production and cytoprotective response. Sci. Rep. 9:5398. https://doi.org/10.1038/s41598-019-41738-5.

Mudgil, P., B. Jobe, H. Kamal, M. Alameri, N. Al Ahbabi, and S. Maqsood. 2019. Dipeptidyl peptidase-IV, $\alpha$-amylase, and angiotensin I converting enzyme inhibitory properties of novel camel skin gelatin hydrolysates. Lebensm. Wiss. Technol. 101:251-258.

Mudgil, P., H. Kamal, B. P. Kilari, M. A. S. M. Salim, C. Y. Gan, and S. Maqsood. 2021. Simulated gastrointestinal digestion of camel and bovine casein hydrolysates: Identification and characterization of novel anti-diabetic bioactive peptides. Food Chem. 353:129374.

Mudgil, P., H. Kamal, G.C. Yuen, and S. Maqsood. 2018. Characterization and identification of novel antidiabetic and anti-obesity peptides from camel milk protein hydrolysates. Food Chem. 259:46-54. https://doi.org/10.1016/j.foodchem.2018.03.082.

Nagarajan, M., S. Benjakul, T. Prodpran, P. Songtipya, and H. Kishimura. 2012. Characteristics and functional properties of gelatin from splendid squid (Loligo formosana) skin as affected by extraction temperatures. Food Hydrocoll. 29:389-397. https://doi .org/10.1016/j.foodhyd.2012.04.001.

Nongonierma, A. B., S. Paolella, P. Mudgil, S. Maqsood, and R. J. FitzGerald. 2018. Identification of novel dipeptidyl peptidase IV (DPP-IV) inhibitory peptides in camel milk protein hydrolysates. Food Chem. 244:340-348. https://doi.org/10.1016/j.foodchem 2017.10.033.

Panwar, H., D. Calderwood, I. R. Grant, S. Grover, and B. D. Green. 2016. Lactobacilli possess inhibitory activity against dipeptidyl peptidase-4 (DPP-4). Ann. Microbiol. 66:505-509. https://doi .org/10.1007/s13213-015-1129-7.

Paula, D. A., E. M. F. Martins, N. A. Costa, P. M. de Oliveira, E. B. de Oliveira, and A. M. Ramos. 2019. Use of gelatin and gum arabic for microencapsulation of probiotic cells from Lactobacillus plantarum by a dual process combining double emulsification followed by complex coacervation. Int. J. Biol. Macromol. 133:722-731. https: //doi.org/10.1016/j.ijbiomac.2019.04.110.

Petraityte, S., and A. Sipailienè. 2019. Enhancing encapsulation efficiency of alginate capsules containing lactic acid bacteria by using different divalent cross-linkers sources. Lebensm. Wiss. Technol. 110:307-315. https://doi.org/10.1016/j.lwt.2019.01.065.

Praepanitchai, O.-A., A. Noomhorm, and A. K. Anal. 2019. Survival and behavior of encapsulated probiotics (Lactobacillus plantarum) in calcium-alginate-soy protein isolate-based hydrogel beads in different processing conditions ( $\mathrm{pH}$ and temperature) and in pasteurized mango juice. Biomed Res. Int. 2019:9768152. https://doi.org/ $10.1155 / 2019 / 9768152$.

Prasanna, P. H. P., and D. Charalampopoulos. 2018. Encapsulation of Bifidobacterium longum in alginate-dairy matrices and survival in simulated gastrointestinal conditions, refrigeration, cow milk and goat milk. Food Biosci. 21:72-79. https://doi.org/10.1016/j.fbio 2017.12.002.

Ptiček Siročić, A., L. Kratofil Krehula, Z. Katančić, and Z. HrnjakMurgić. 2016. Characterization of casein fractions-Comparison of commercial casein and casein extracted from cow's milk. Chem. Biochem. Eng. Q. 30:501-509. https://doi.org/10.15255/CABEQ .2015.2311.

Sannasiddappa, T. H., P. A. Lund, and S. R. Clarke. 2017. In vitro antibacterial activity of unconjugated and conjugated bile salts on Staphylococcus aureus. Front. Microbiol. 8:1581. https://doi.org/ 10.3389/fmicb.2017.01581.

Sarabandi, K., A. Sadeghi Mahoonak, H. Hamishekar, M. Ghorbani, and S. M. Jafari. 2018. Microencapsulation of casein hydrolysates:
Physicochemical, antioxidant and microstructure properties. J. Food Eng. 237:86-95. https://doi.org/10.1016/j.jfoodeng.2018.05 .036 .

Singh, M., D. Sharma, R. Chauhan, and G. Goel. 2019. Skimmed milk-based encapsulation for enhanced stability and viability of Lactobacillus gastricus BTM 7 under simulated gastrointestinal conditions. Probiotics Antimicrob. Proteins 11:850-856. https:// doi.org/10.1007/s12602-018-9472-1.

Socrates, G. 2004. Infrared and Raman Characteristic Group Frequencies: Tables and Charts. John Wiley \& Sons.

Tavares, G. M., T. Croguennec, A. F. Carvalho, and S. Bouhallab. 2014. Milk proteins as encapsulation devices and delivery vehicles: Applications and trends. Trends Food Sci. Technol. 37:5-20. https: //doi.org/10.1016/j.tifs.2014.02.008.

Vaziri, A. S., I. Alemzadeh, M. Vossoughi, and A. C. Khorasani. 2018 Co-microencapsulation of Lactobacillus plantarum and DHA fatty acid in alginate-pectin-gelatin biocomposites. Carbohydr. Polym. 199:266-275. https://doi.org/10.1016/j.carbpol.2018.07.002.

Yao, M., B. Li, H. Ye, W. Huang, Q. Luo, H. Xiao, D. J. McClements, and L. Li. 2018. Enhanced viability of probiotics (Pediococcus pentosaceus Li05) by encapsulation in microgels doped with inorganic nanoparticles. Food Hydrocoll. 83:246-252. https://doi.org/10 .1016/j.foodhyd.2018.05.024.

Yao, M., J. Wu, B. Li, H. Xiao, D. J. McClements, and L. Li. 2017. Microencapsulation of Lactobacillus salivarious Li01 for enhanced storage viability and targeted delivery to gut microbiota. Food Hydrocoll. 72:228-236. https://doi.org/10.1016/j.foodhyd.2017.05 .033 .

Yeo, S.-K., J.-A. Ewe, C. S.-C. Tham, and M.-T. Liong. 2011. Carriers of probiotic microorganisms. Pages 191-220 in Probiotics. Springer.

Zeng, Z., J. Y. Luo, F. L. Zuo, R. Yu, Y. Zhang, H. Q. Ma, and S.W. Chen. 2016b. Bifidobacteria possess inhibitory activity against dipeptidyl peptidase-IV. Lett. Appl. Microbiol. 62:250-255. https:// doi.org/10.1111/lam.12510.

Zeng, Z., J. Luo, F. Zuo, Y. Zhang, H. Ma, and S. Chen. 2016a. Screening for potential novel probiotic Lactobacillus strains based on high dipeptidyl peptidase IV and $\alpha$-glucosidase inhibitory activity. J. Funct. Foods 20:486-495. https://doi.org/10.1016/j.jff 2015.11.030.

Zhang, B., Z. Deng, D. D. Ramdath, Y. Tang, P. X. Chen, R. Liu, Q. Liu, and R. Tsao. 2015. Phenolic profiles of 20 Canadian lentil cultivars and their contribution to antioxidant activity and inhibitory effects on $\alpha$-glucosidase and pancreatic lipase. Food Chem. 172:862-872. https://doi.org/10.1016/j.foodchem.2014.09.144.

Zhao, M., X. Huang, H. Zhang, Y. Zhang, M. Gänzle, N. Yang, K. Nishinari, and Y. Fang. 2020. Probiotic encapsulation in water-inwater emulsion via heteroprotein complex coacervation of type-A gelatin/sodium caseinate. Food Hydrocoll. 105:105790. https://doi .org/10.1016/j.foodhyd.2020.105790.

Zhao, M., Y. Wang, X. Huang, M. Gaenzle, Z. Wu, K. Nishinari, N. Yang, and Y. Fang. 2018. Ambient storage of microencapsulated Lactobacillus plantarum ST-III by complex coacervation of type-A gelatin and gum arabic. Food Funct. 9:1000-1008. https://doi.org/ 10.1039/C7FO01802A

\section{ORCIDS}

Priti Mudgil ๑ https://orcid.org/0000-0003-0809-485X Fathala Hamed ๑ https://orcid.org/0000-0001-7191-2136 Sajid Maqsood @ https://orcid.org/0000-0003-2099-8392 